\title{
Verification of the shear performance of mortise and tenon joints with top and bottom notches at the beam end
}

\author{
Shigefumi Okamoto ${ }^{*^{*}}$ (D) Makoto Nakatani ${ }^{2}$, Nobuhiko Akiyama ${ }^{3}$, Kei Tanaka ${ }^{4}$ and Takuro Mori ${ }^{5}$
}

\begin{abstract}
Shear experiments on mortise and tenon joints with top and bottom notches in the beam end were conducted with the length of the tenon as a variable. In addition, material experiments were performed to investigate the structural performance of the fracture modes of the joint. The experimental results show that when the lower notch at the beam end experiences splitting, the shear forces were identical for different tenon lengths and did not decrease. In addition, the deformation performance of the joint up to yielding was largely due to the compressive deformation perpendicular to the grain of the wood on the sides of the tenon. Based on the theory of the calculation method of the splitting strength of a notched beam, a formula for the splitting strength when the end of the beam is momentresisting was proposed. It was confirmed that the proposed formula could estimate the shear force that caused the splitting fracture of the lower notch. In addition, the increase in shear force after the lower notch experienced splitting fracture was due to the increase in clamping force of the beam end due to rotational deformation.
\end{abstract}

Keywords: Glued laminated timber, Mortise and tenon joint, Shear performance, Compression perpendicular to grain, Splitting

\section{Introduction}

In Japan, there is a growing trend toward the use of wood in medium- to large-scale buildings. As part of this trend, there has been a great deal of research on momentresisting timber joints. The results are summarized in the "Design Manual for Engineered Timber Joints" [1] and other publications. Some moment-resisting joints use joints that resist tensile axial forces, such as lag-screw bolts [2] and glued-in rods [3]. Such joints resist shear force through the friction of the compressive force at the end of the beam generated by bending. However, frictional resistance cannot be guaranteed when the moment acting on the beam is small or after the beam fails due to bending. Therefore, the "Design Manual for Engineered

\footnotetext{
*Correspondence: sgfmokmt@gmail.com

${ }^{1}$ Graduate School of Human Life Science, Osaka City University, 3-3-138

Sugimoto, Sumiyoshi-ku, Osaka 558-8585, Japan

Full list of author information is available at the end of the article
}

Timber Joints" [1] states that a different resistance mechanism is needed to resist shear forces. In the case of beam end joints, the joint is often made of a steel connection joint to facilitate construction. When a steel connection joint is used, notches are installed at the top and bottom of the beam end, as shown in Fig. 1. However, there is no previous research on uniquely shaped joints with notches at the top and bottom of the beam end, and the performance of such joints is not known. Therefore, in this study, the shear performance of mortise and tenon joints with top and bottom notches at the beam end was analyzed.

For mortise and tenon joints, the structural performance related to the tensile resistance $[4,5]$, moment resistance $[6,7]$ and shear resistance $[8,9]$ have been reported. Other special cases have also been reported, such as structural performance with wood angles of $30^{\circ}, 45^{\circ}$ and $60^{\circ}[10]$ and shear resistance with multiple mortise and tenon joints [11]. Gamerro et al. [8] and 


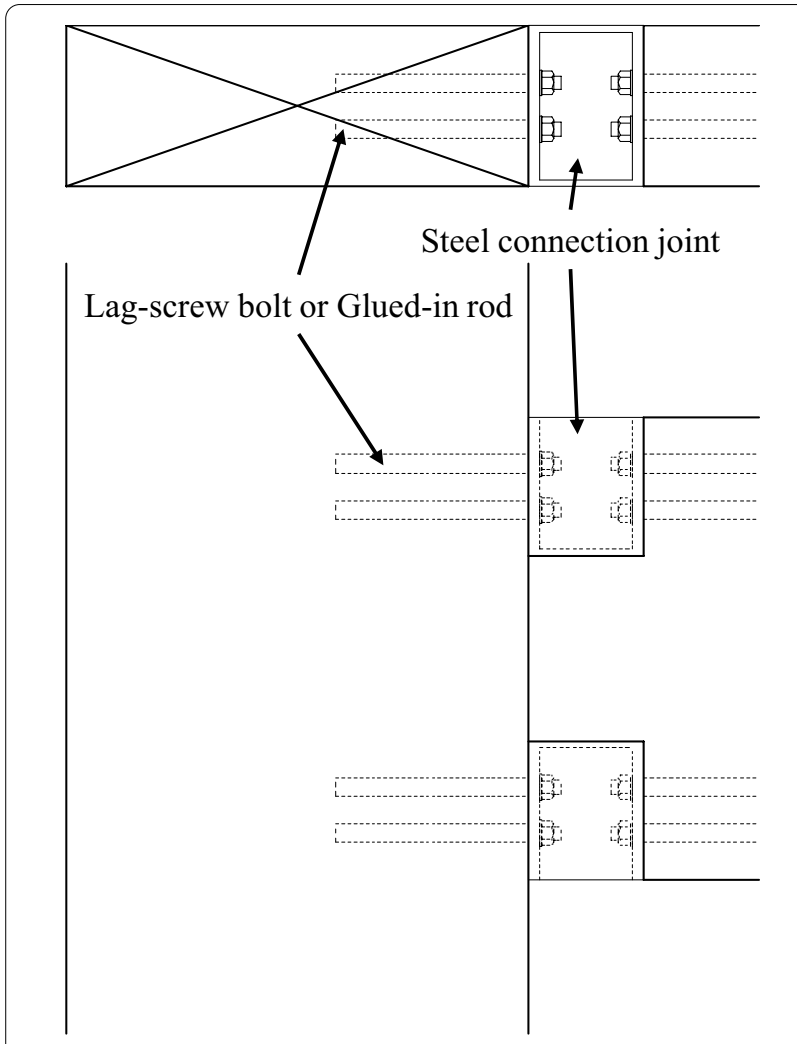

Fig. 1 Moment-resisting timber joint

Tsukazaki et al. [9] studied the methods of estimating the bearing capacity of the joints by classifying the failure modes to determine the shear performance of mortise and tenon joints. Although there is no previous research on a joint with notches at the top and bottom of the beam end, we can predict the actual possible failure modes of the joint by referring to the reports of Gamelro et al. [8] and Tsukazaki et al. [9]. If we exclude the failure modes that are expected to have very high bearing capacity, we can assume that there are two types of failure modes, as shown in Fig. 2. Figure 2a shows the compression failure perpendicular to the grain on the side of the tenon. Figure $2 \mathrm{~b}$ shows a splitting fracture at the notch. In this study, we conducted a shear experiment on a mortise and tenon joint with notches at the top and bottom of the beam end and compared the shear performance of the joint with the structural performance of the failure mode shown in Fig. 2 to analyze the shear performance in detail.

\section{Materials and methods}

\section{Shear performance of the joint}

A schematic diagram of the joint shear experiment and the beam end is shown in Fig. 3. Glued laminated timber composed of mixed-grade laminae (symmetrical

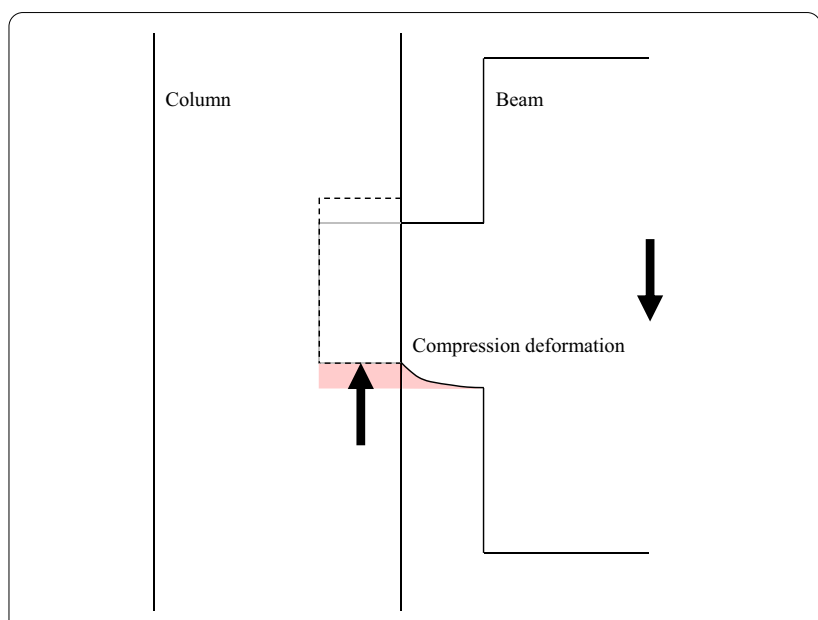

a Compression failure perpendicular to the grain of the tenon
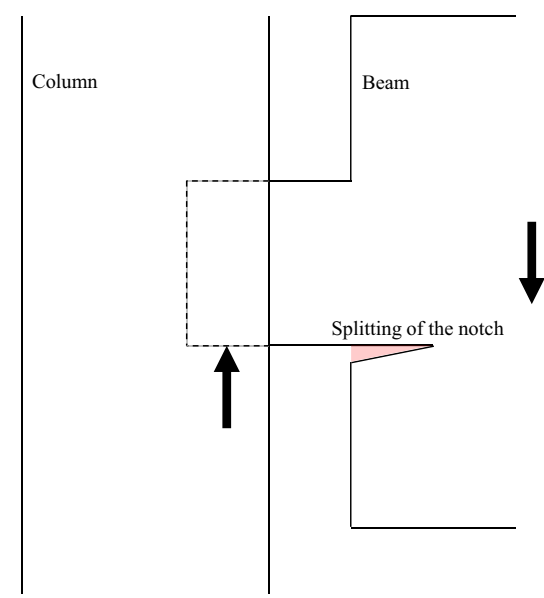

b Splitting fracture of the notch

Fig. 2 Fracture mode of a mortise and tenon joint with notches at the top and bottom of the beam end

composition, strength grade E65-F225) is used as the material, as specified by the Japanese Agricultural Standard [12] for Japanese cedar (Cryptomeria japonica). The cross-sectional area of the columns is $210 \mathrm{~mm} \times 300 \mathrm{~mm}$, and that of the beams is $210 \mathrm{~mm} \times 600 \mathrm{~mm}$. Notches and a tenon are provided at the end of the beam. The width of the tenon is $105 \mathrm{~mm}$, which is half of the beam width, and the tenon lengths are $100 \mathrm{~mm}(\mathrm{~J}-\mathrm{L} 100)$ and $150 \mathrm{~mm}$ (J-L150). The beam end is notched $180 \mathrm{~mm} \times 150 \mathrm{~mm}$ at the top and bottom. There are three specimens for each tenon length. The mean and standard deviation values of the density are $399 \pm 4 \mathrm{~kg} / \mathrm{m}^{3}$ for the beams and $403 \pm 8 \mathrm{~kg} / \mathrm{m}^{3}$ for the columns. The density is the weight of the specimen divided by the volume. The mean and 


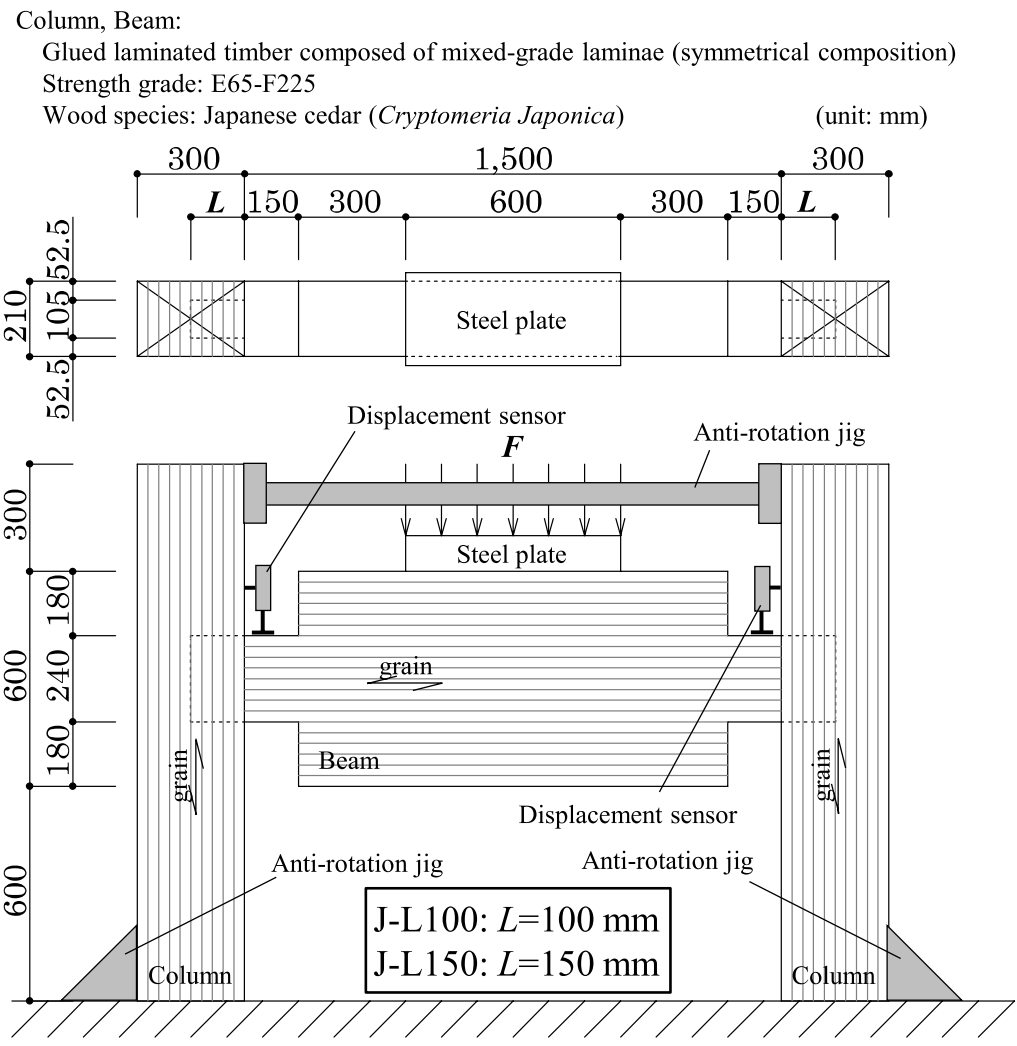

a Schematic diagram

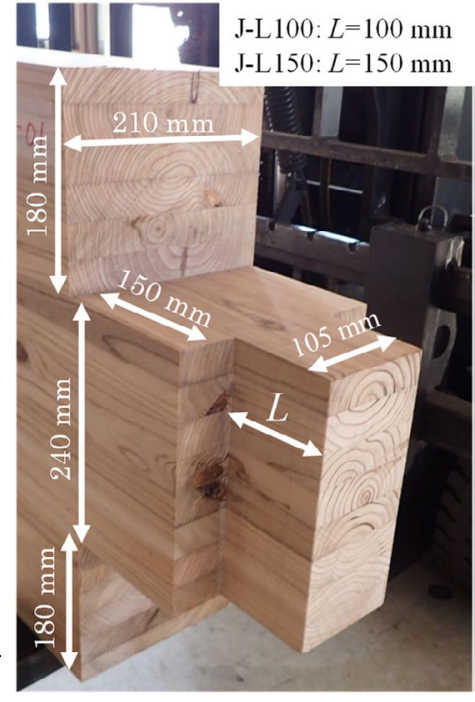

b Processing of the beam end

Fig. 3 Shear test of the joint

standard deviation values of the moisture content are $11.2 \pm 1.3 \%$ for the beams and $13.1 \pm 0.5 \%$ for the columns. The moisture content was measured by a moisture meter (HM-520, Kett Electric Laboratory).

For the experiment, the load was applied at a constant crosshead speed of $3 \mathrm{~mm} / \mathrm{min}$. Displacement was measured as the relative displacement of the column and beam at the joint. The specimens were equipped with anti-rotation jigs at the top and bottom to prevent the columns from rotating under an applied force.

\section{Splitting strength of the notch at the beam}

Gustafsson [13] proposed an equation for calculating the bearing capacity of crack fractures in notched beams. It was derived by modeling the crack growth by increasing the notch length. However, the formula to calculate the bearing capacity of notched beams [13] is not applicable to moment-resisting mortise and tenon joints [6, 7] because it assumes that the moment acting at the end of the beam is zero. Therefore, a bearing capacity formula for the case of moment resistance at the end of the beam was derived using the same concept as that of the notched beam bearing capacity formula [13].

A schematic of the notched beam model is shown in Fig. 4. Figure 4a shows the external forces acting on the beam, and Fig. 4b shows the moment diagram. As shown in Fig. $4 \mathrm{c}$, when a crack of length $D \Delta \beta$ occurs, it is assumed that the part of the beam below the crack does not contribute to the stiffness of the beam. The increase $\Delta \delta$ in deflection at the load location at crack length $D \Delta \beta$ is then the sum of the increase $\Delta \delta_{\mathrm{s}}$ in deflection due to shear deformation of the beam and the increase $\Delta \delta_{\mathrm{b}}$ in deflection due to bending deformation of the beam.

When the shear force $Q$ and bending moment $M$ are constant and a crack occurs of length $D \Delta \beta$, the increase $\Delta \delta$ in deflection at the load location can be expressed by Eqs. (1-3):

$$
\begin{aligned}
& \Delta \delta=\Delta \delta_{\mathrm{s}}+\Delta \delta_{\mathrm{b}} \\
& \Delta \delta_{\mathrm{s}}=\frac{1.2}{G_{x y}}\left(\frac{\Delta \beta}{B \alpha}-\frac{\Delta \beta}{B}\right) P,
\end{aligned}
$$



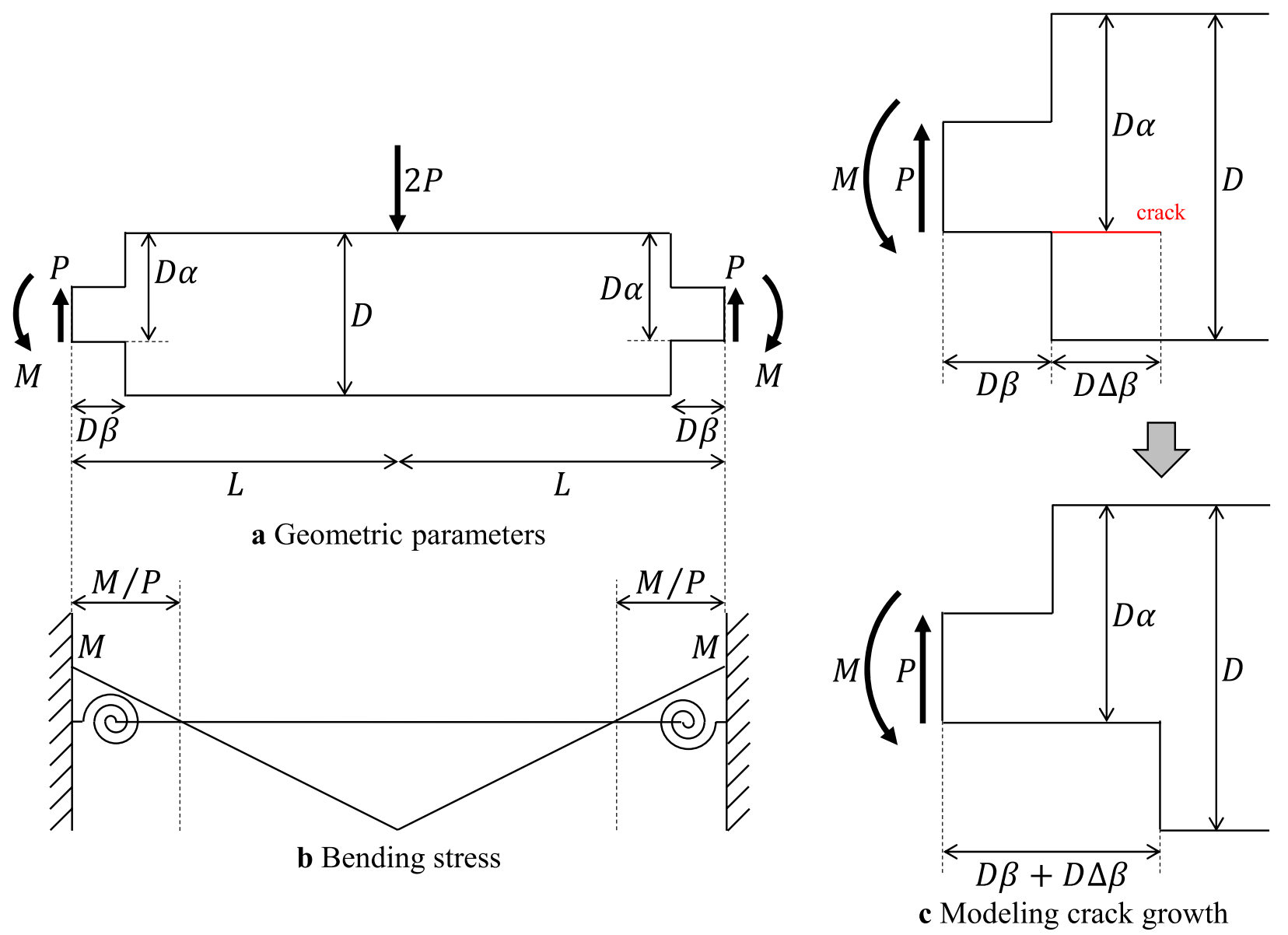

Fig. 4 Schematic diagram of the model of the beam with a notch

$$
\begin{aligned}
\Delta \delta_{\mathrm{b}}= & \frac{P}{E_{x} B D^{3} / 12}\left(\frac{1}{\alpha^{3}}-1\right)\left(\frac{D^{3} \Delta \beta^{3}+3 D^{3} \beta^{2} \Delta \beta+3 D^{3} \beta \Delta \beta^{2}}{3}\right) \\
& -\frac{M}{E_{x} B D^{3} / 12}\left(\frac{1}{\alpha^{3}}-1\right)\left(\frac{D^{2} \Delta \beta^{2}+3 D^{2} \beta \Delta \beta}{2}\right)
\end{aligned}
$$

where $B$ is the beam width, $E_{x}$ is Young's modulus parallel to the grain, and $G_{x y}$ is the shear modulus.

Then, the loss in potential energy $\Delta W$ when a crack of length $D \Delta \beta$ occurs can be expressed by Eq. (4):

$$
\Delta W=0.5 P \Delta \delta=G_{\mathrm{c}} B D \Delta \beta,
$$

where $G_{\mathrm{c}}$ is the mode I fracture energy.

Using Eqs. (1-4) and setting $\Delta \beta \rightarrow 0$, we can obtain the formula for calculating the resistance to crack fracture in Eq. (5):

$$
P=\frac{B D \alpha \sqrt{G_{c} / D}}{\sqrt{0.6\left(\alpha-\alpha^{2}\right) / G_{x y}+6 \beta^{2}\left(1 / \alpha-\alpha^{2}\right) / E_{x}-9 \beta\left(1 / \alpha-\alpha^{2}\right)(M / P)\left(E_{x} D\right)}} .
$$

Since $\Delta \delta$ is the deformation in the range of $D \Delta \beta$, the notch at the top of the beam end has no effect on the performance. The notch length plus the crack length are combined as $D \beta$ (Fig. 5), and the bearing capacity after the crack occurs can be calculated using Eq. (5).

In the formula for calculating the bearing capacity of notched beams [13], the increase $\Delta \delta$ in deflection is $\Delta \delta_{\mathrm{s}}+\Delta \delta_{\mathrm{b}}+\Delta \delta_{\mathrm{r}}$ to account for the increase $\Delta \delta_{\mathrm{r}}$ in deflection due to the reduced clamping stiffness at the transition between the full cross-section and reduced cross-section. However, Smith et al. [14] derived an equation for calculating the bearing capacity of a notched 

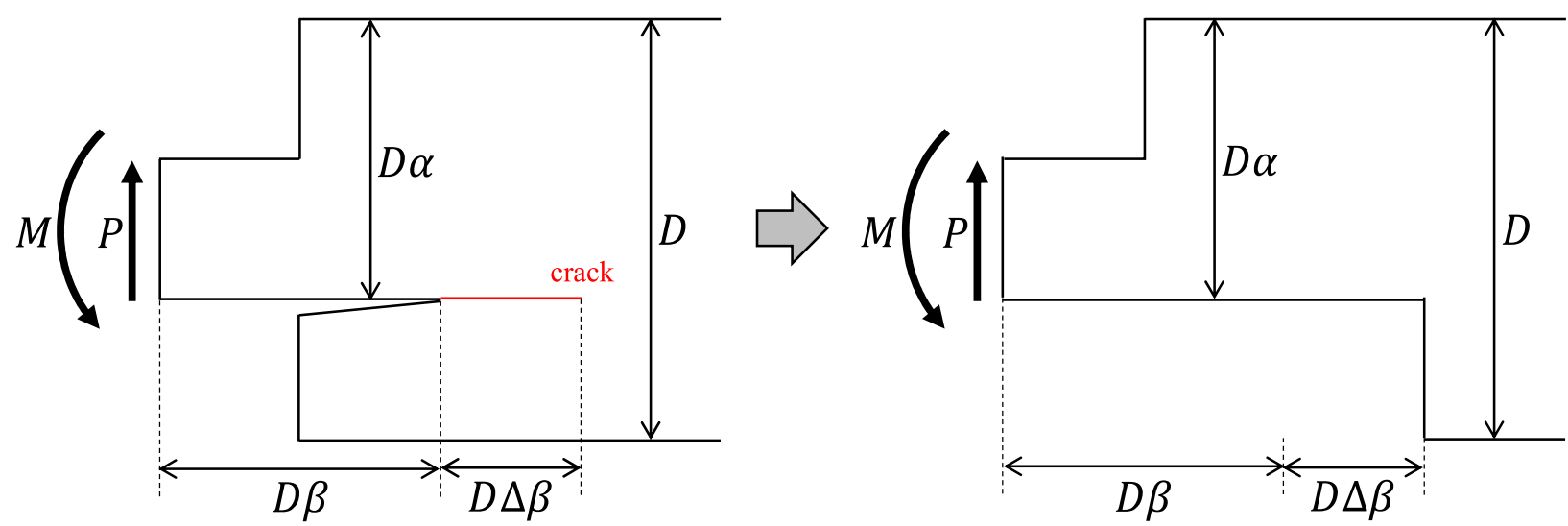

Fig. 5 Modeling of the crack after the crack initiation at the beam end

beam with the increase $\Delta \delta$ in deflection as $\Delta \delta_{\mathrm{s}}+\Delta \delta_{\mathrm{b}}$. They also reported that the formula agrees well with the finite element calculations when the increase $\Delta \delta$ in deflection is $\Delta \delta_{\mathrm{s}}+\Delta \delta_{\mathrm{b}}$. Therefore, in this study, we determined that $\Delta \delta=\Delta \delta_{\mathrm{s}}+\Delta \delta_{\mathrm{b}}$ was applicable and proposed Eq. (5). Other reasons for using $\Delta \delta=\Delta \delta_{\mathrm{s}}+\Delta \delta_{\mathrm{b}}$ were to simplify the equation and to calculate the bearing capacity after cracking using Eq. (5).

\section{Mode I fracture energy}

The fracture energy $G_{c}$ used in Eq. (5) is obtained by a single-edge-notched bending test [15]. A schematic diagram of the experiment is shown in Fig. 6. Glued laminated timber composed of mixed-grade laminae (symmetrical composition, strength grade E65-F225) as specified by the Japanese Agricultural Standard [12] for Japanese cedar (Cryptomeria japonica) was used as the material. The test specimens were taken from laminated wood manufactured with cross-sections with a width of $210 \mathrm{~mm}$ and height of $600 \mathrm{~mm}$. The width of the specimen was $103 \mathrm{~mm}$, which is half of the width of the glued laminated timber due to the experimental setup. The notch in the specimen was made at the location of the inner lamina of the glued laminated timber. Eight specimens were tested for each design: one design with a notch in the center of the lamina (Fig. 7a) and one with a notch in the adhesive layer (Fig. 7b). The mean \pm standard deviation of the density of the inner lamina near the notch was $384 \pm 18 \mathrm{~kg} / \mathrm{m}^{3}$ for the specimen with a notch in the center of the lamina and $386 \pm 15 \mathrm{~kg} / \mathrm{m}^{3}$ for the specimen with a notch in the adhesive layer. The mean \pm standard deviation of the moisture content of the inner lamina near the notch was $8.8 \pm 0.9 \%$ for the specimen with a notch in the center of the lamina and $8.8 \pm 1.0 \%$ for the specimen with a notch in the adhesive layer. After the experiment, samples were cut out to measure the density and moisture content. The moisture content was measured using a moisture tester (HM-520, Kett Electric Laboratory). For the experiment, the load was applied at a constant crosshead speed of $1 \mathrm{~mm} / \mathrm{min}$, and the load and displacement of the crosshead were measured.

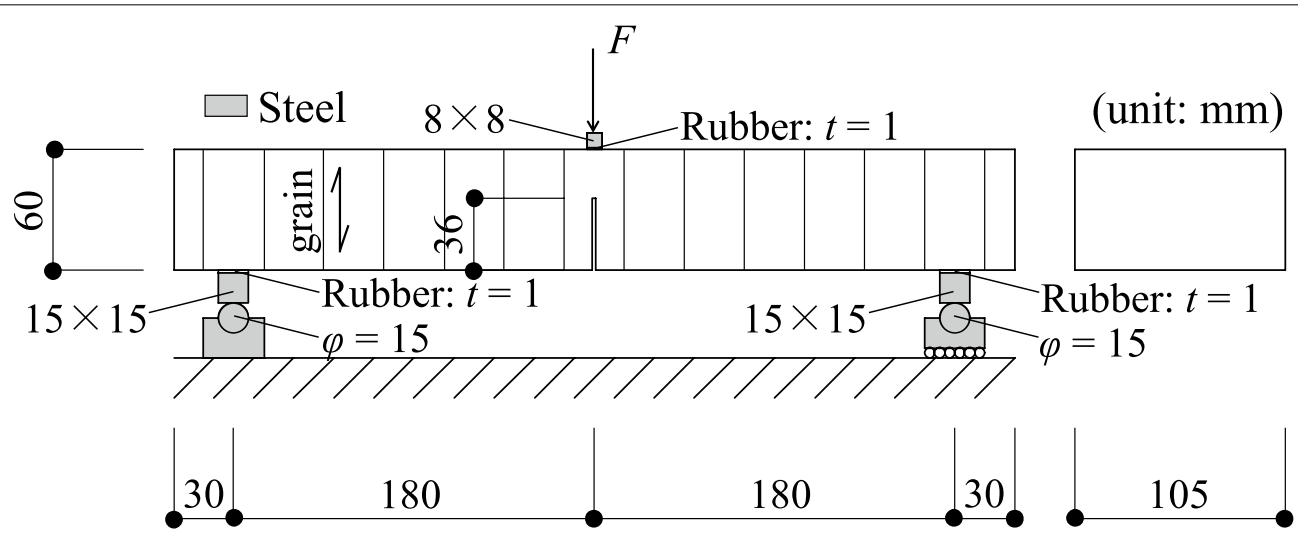

Fig. 6 Schematic diagram of the single-edge-notched bending test 


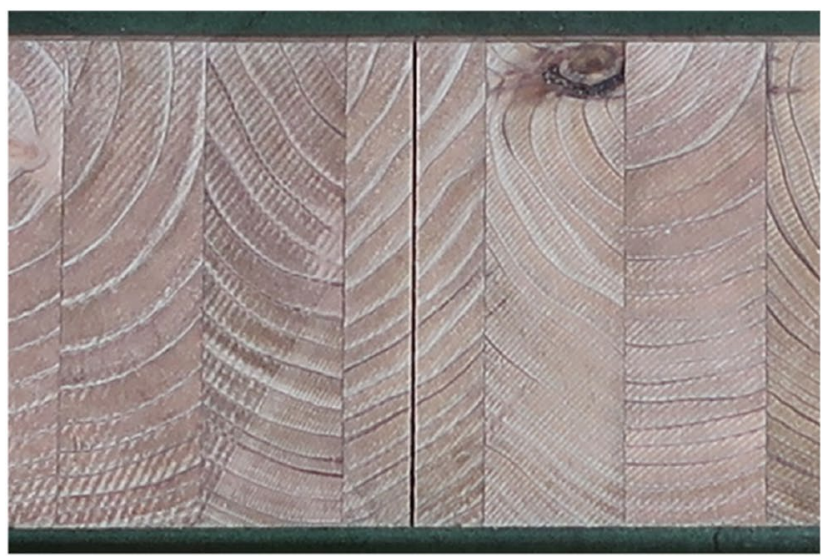

a Specimen with a notch in the center of the lamina

Fig. 7 Lower surface of the representative specimen

\section{Compression performance perpendicular to the grain of the tenon}

The compression performance perpendicular to the grain of the tenon was determined by the experiment. A schematic diagram of the experiment used to determine the compression performance perpendicular to the grain is shown in Fig. 8. C-H200 (Fig. 8a) is an experiment conducted to check the compression performance perpendicular to the grain of the side of the tenon of J-L100, and the number of specimens is two. An experiment to check the compression performance perpendicular to the grain of the side of the tenon of J-L150 is not conducted because the specimens could not be cut out. Experiments C-I200 and C-I300 (Fig. 8b, c) were conducted to check the performance of $\mathrm{C}-\mathrm{H} 200$ (Fig. 8a) when there was no extra length in the width direction, and there were three specimens for each test. Experiments C-200 and C-300 (Fig. 8d, e) were conducted to confirm the performance when the bottom surface was fully supported, and there were six specimens for each test. To achieve identical performance to C-I200 and C-I300, the heights of C-200 and $\mathrm{C}-300$ were halved to $120 \mathrm{~mm}$ based on the experimental results of Ido et al. [16]. These specimens were cut from the specimens in the joint shear experiments (Fig. 9). The mean and standard deviation of the density were $381 \pm 1 \mathrm{~kg} / \mathrm{m}^{3}$ for $\mathrm{C}-\mathrm{H} 200,389 \pm 2 \mathrm{~kg} / \mathrm{m}^{3}$ for C-I200, $386 \pm 14 \mathrm{~kg} / \mathrm{m}^{3}$ for C-I300, $400 \pm 8 \mathrm{~kg} / \mathrm{m}^{3}$ for C-200, and $399 \pm 11 \mathrm{~kg} / \mathrm{m}^{3}$ for $\mathrm{C}-300$. The density is the weight of the specimen divided by the volume. The mean and standard deviation values of the moisture content were $10.2 \pm 0.2 \%$ for C-H200, $10.1 \pm 0.2 \%$ for C-I200, $10.3 \pm 0.3 \%$ for C-I300, $13.5 \pm 0.2 \%$ for C-200, and $13.3 \pm 0.2 \%$ for C-300. The moisture content was measured by a moisture meter (HM-520, Kett Electric Laboratory).

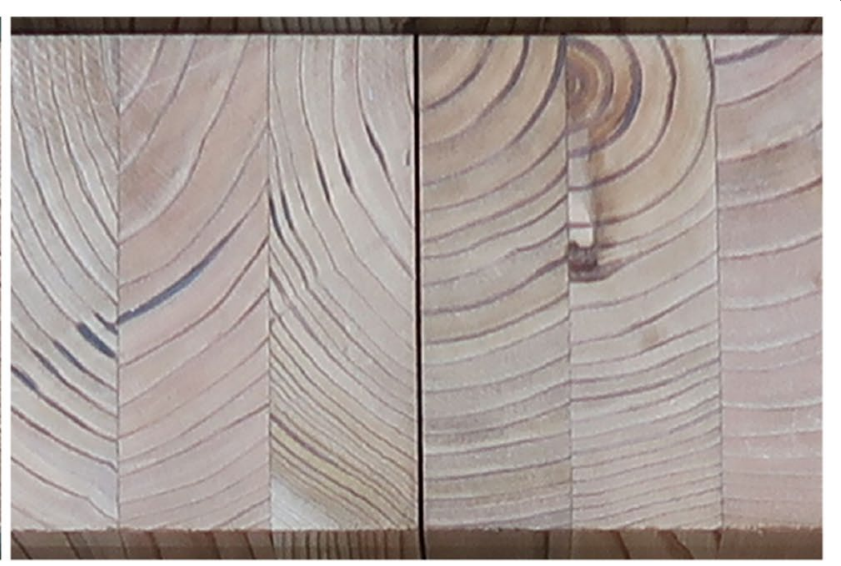

b Specimen with a notch in the adhesive layer

For the experiment, the load was applied at a constant crosshead speed of $3 \mathrm{~mm} / \mathrm{min}$. The displacement was measured as the relative displacement between the crosshead and the underside of the specimen at the loading point.

\section{Results and discussion}

\section{Shear performance of the joint}

Figures 10, 11, 12, 13, 14 and 15 show the final fracture status of the specimen. The visually confirmed fractures occurred in the following order: (1) crack in the lower notch, (2) crack below the center of the beam, and (3) crack above the center of the beam. The fracture in (1) simultaneously occurred at the left and right joints. When the deformation increased, the lower part of the beam end was in contact with the column as the beam end rotated due to bending deformation and deformation caused by cracking at the lower notch. In the final fractured joint in Figs. 10, 11, 12, 13, 14 and 15, the bottom of the beam end and the column are not in contact, but they were in contact before the final fracture appeared. Figure 16 shows the relationship between shear force $P$ and displacement $\delta$ at the joint. The location of the $P$ and $\delta$ of the first visible fracture at either side of the joint is also shown in Fig. 16. $P$ at the joint is $1 / 2$ of the force point load $F . \delta$ is the relative displacement between the column and the end of the beam. Table 1 shows the results of the $P-\delta$ relationship evaluated by the elastic-perfectly plastic model [17], which is evaluated in terms of the $P-\delta$ relationship with a maximum displacement of $30 \mathrm{~mm}$.

Cracking at the bottom of the notch was observed first during the shear test of the joint, which was visually 

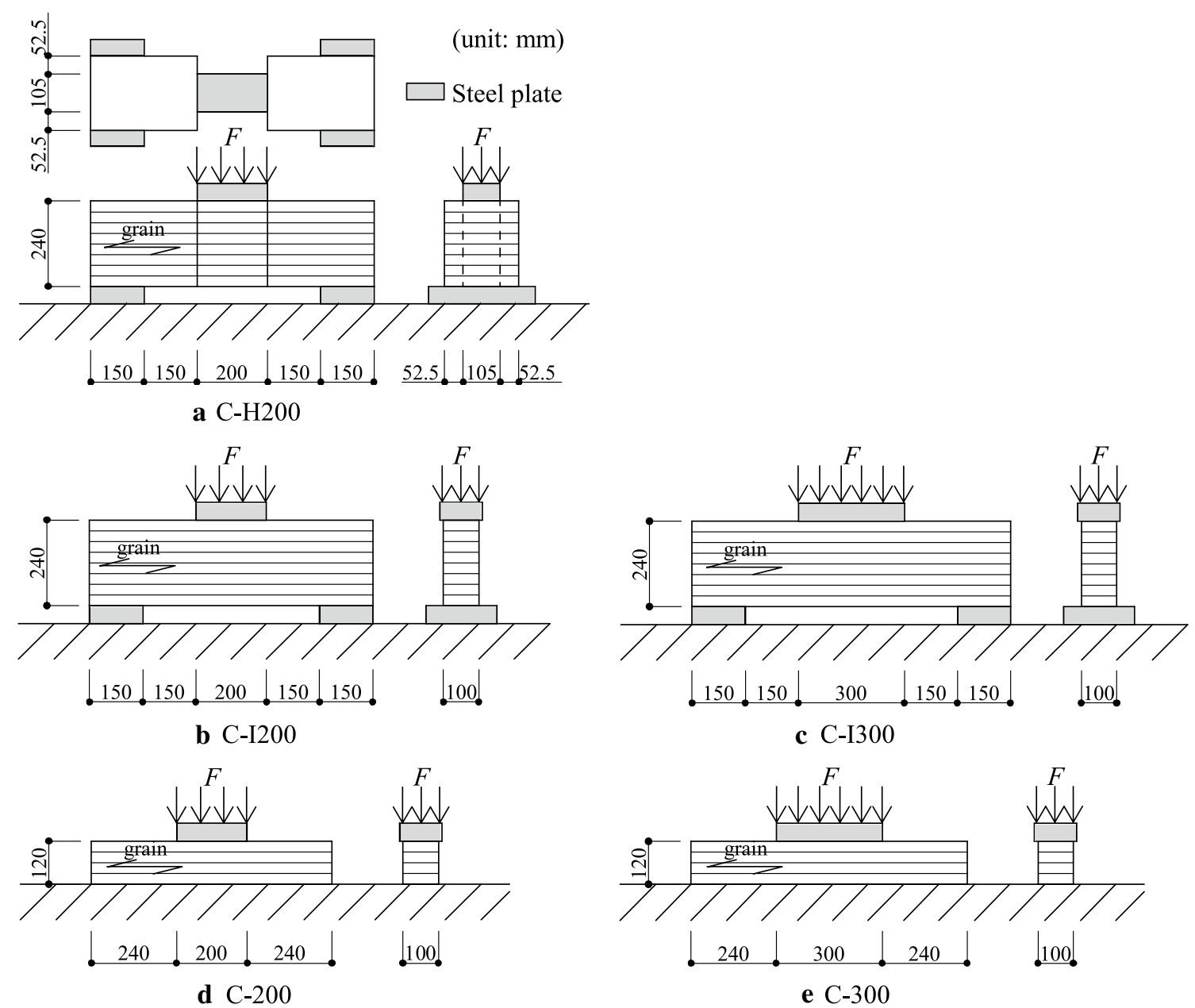

Fig. 8 Schematic diagram of loading perpendicular to the grain compression test

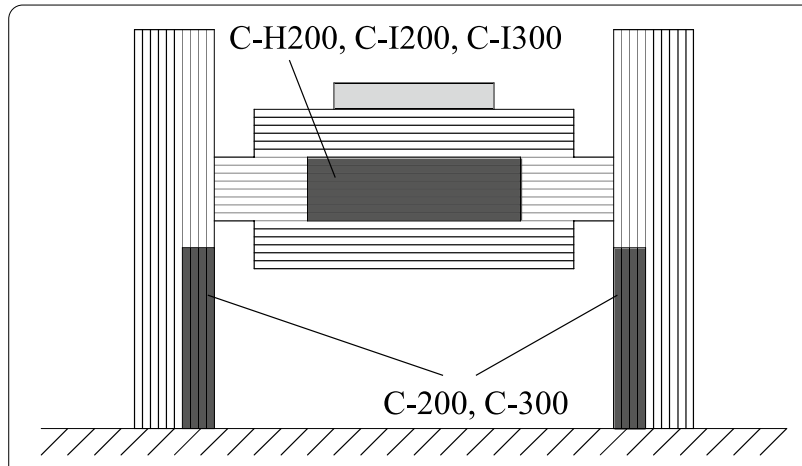

Fig. 9 Schematic diagram of the compression specimen sampling location perpendicular to the grain

observed when $P$ was approximately $80 \mathrm{kN}$ for both J-L100 and J-L150. For a notched beam, as soon as a crack occurs, the crack lengthens, and the load decreases
[18]. However, for this specimen, $P$ did not decrease due to cracking at the lower notch, and the cracks gradually lengthened as $P$ increased. This may be due to the moment resistance caused by the contact between the lower beam end and the column, which increased the splitting resistance. Another factor may be the different load-carrying mechanism of shear and bending in the short beam compared to the long beam. In addition, J-L100 and J-L150 No. 2 had joints where no splitting occurred at the lower notch, which may also be due to the moment resistance at the beam end. Next, a crack below the center of the beam was visually confirmed at $\delta$ of approximately $40-50 \mathrm{~mm}$ for J-L100 and $\delta$ of approximately 10-15 $\mathrm{mm}$ for J-L150. The crack below the center of the beam gradually lengthened when the crack displacement increased. A crack below the center of the beam did not occur in some joints. Finally, a crack above the center of the beam was visually confirmed, and 

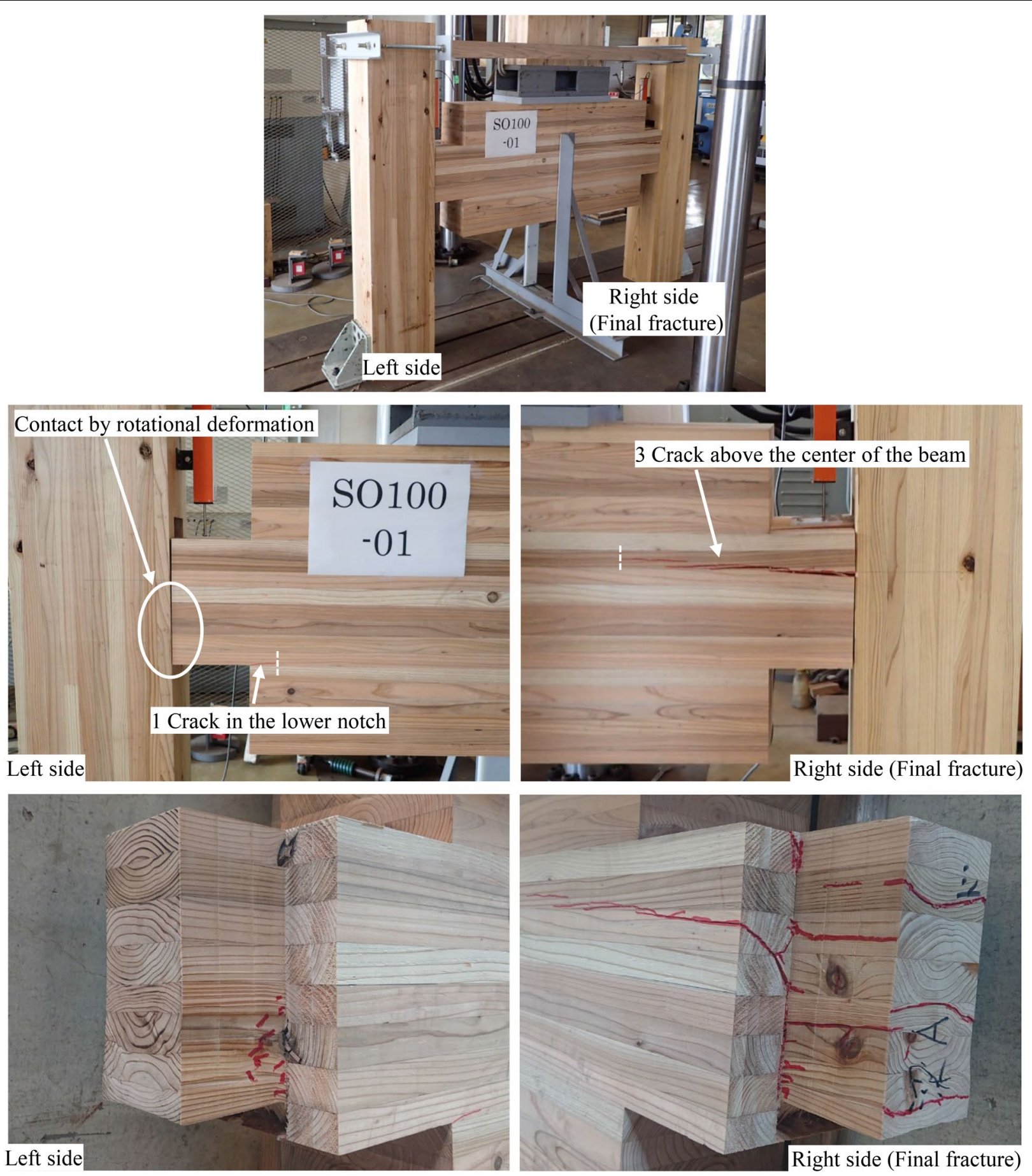

Fig. 10 Final fracture state of the specimen (J-L100, No. 1) 


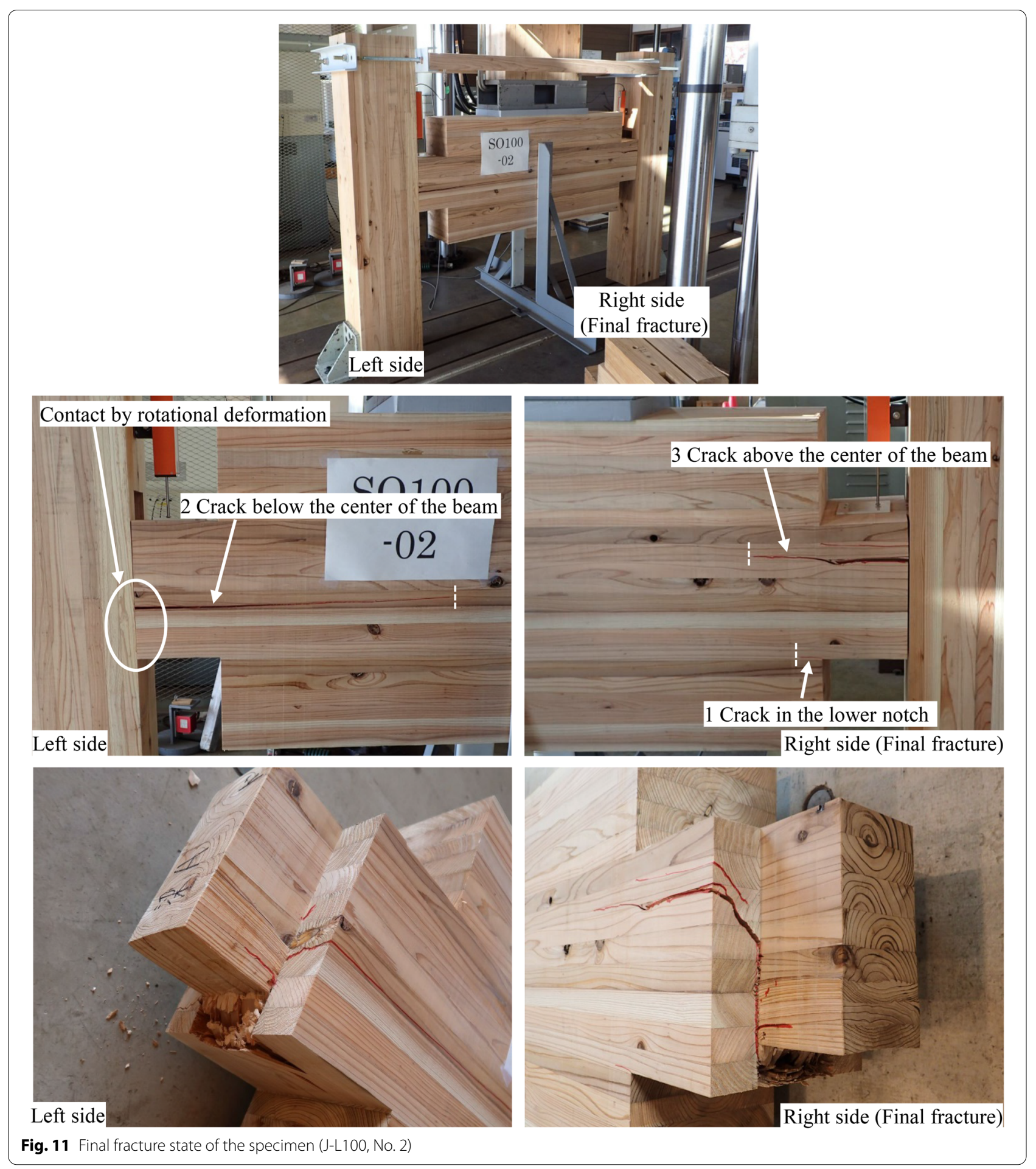



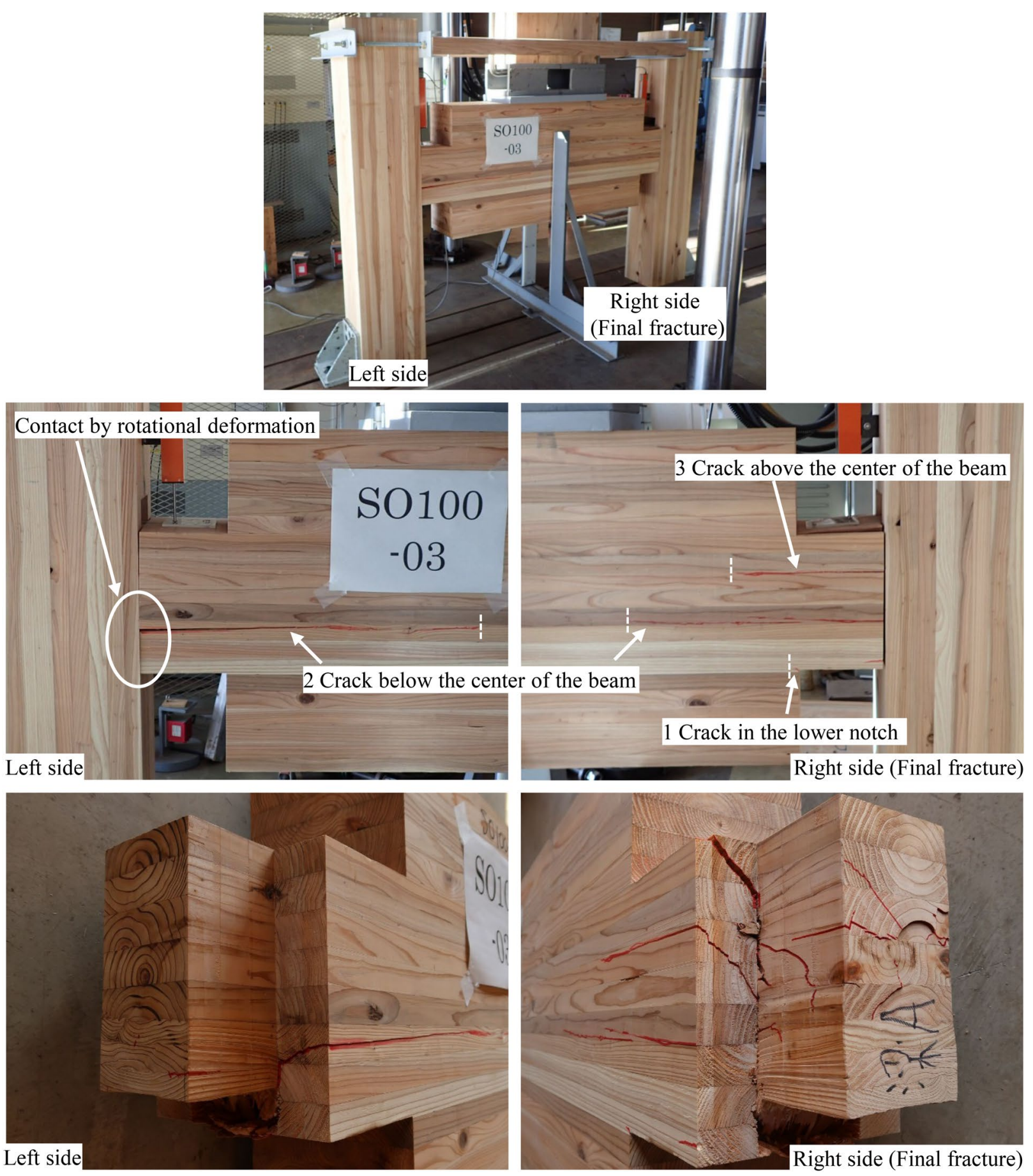

Fig. 12 Final fracture state of the specimen (J-L100, No. 3) 


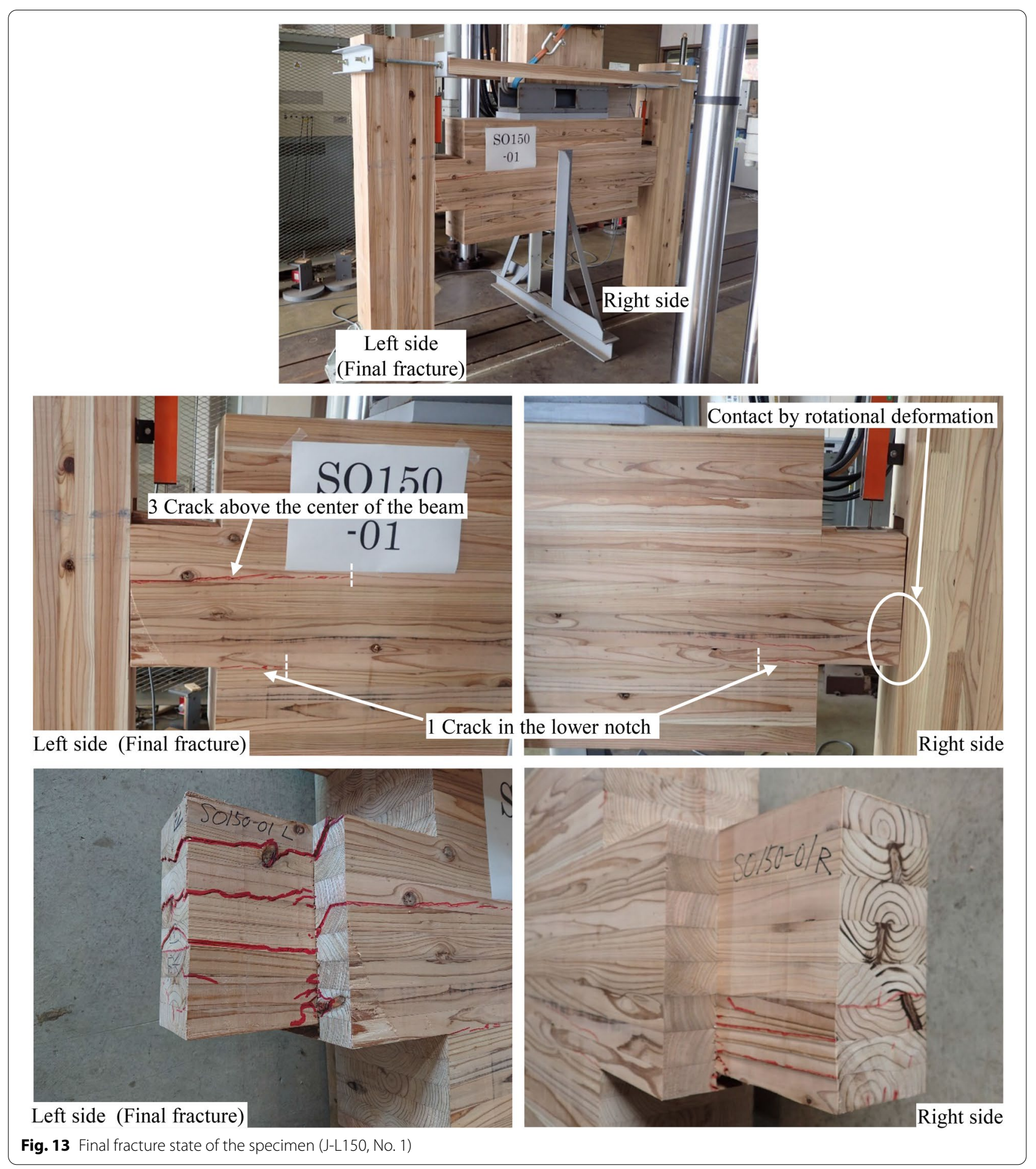




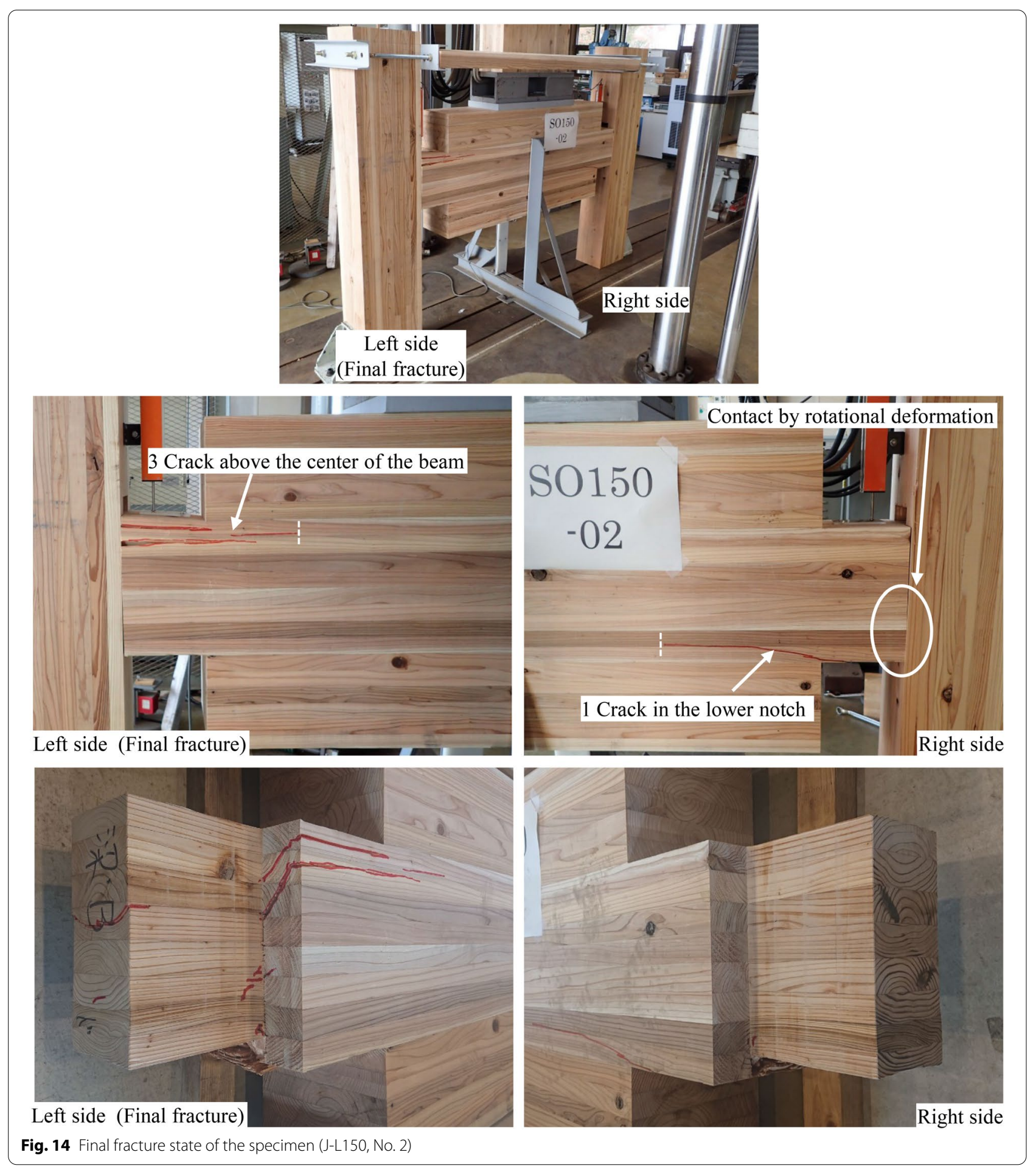




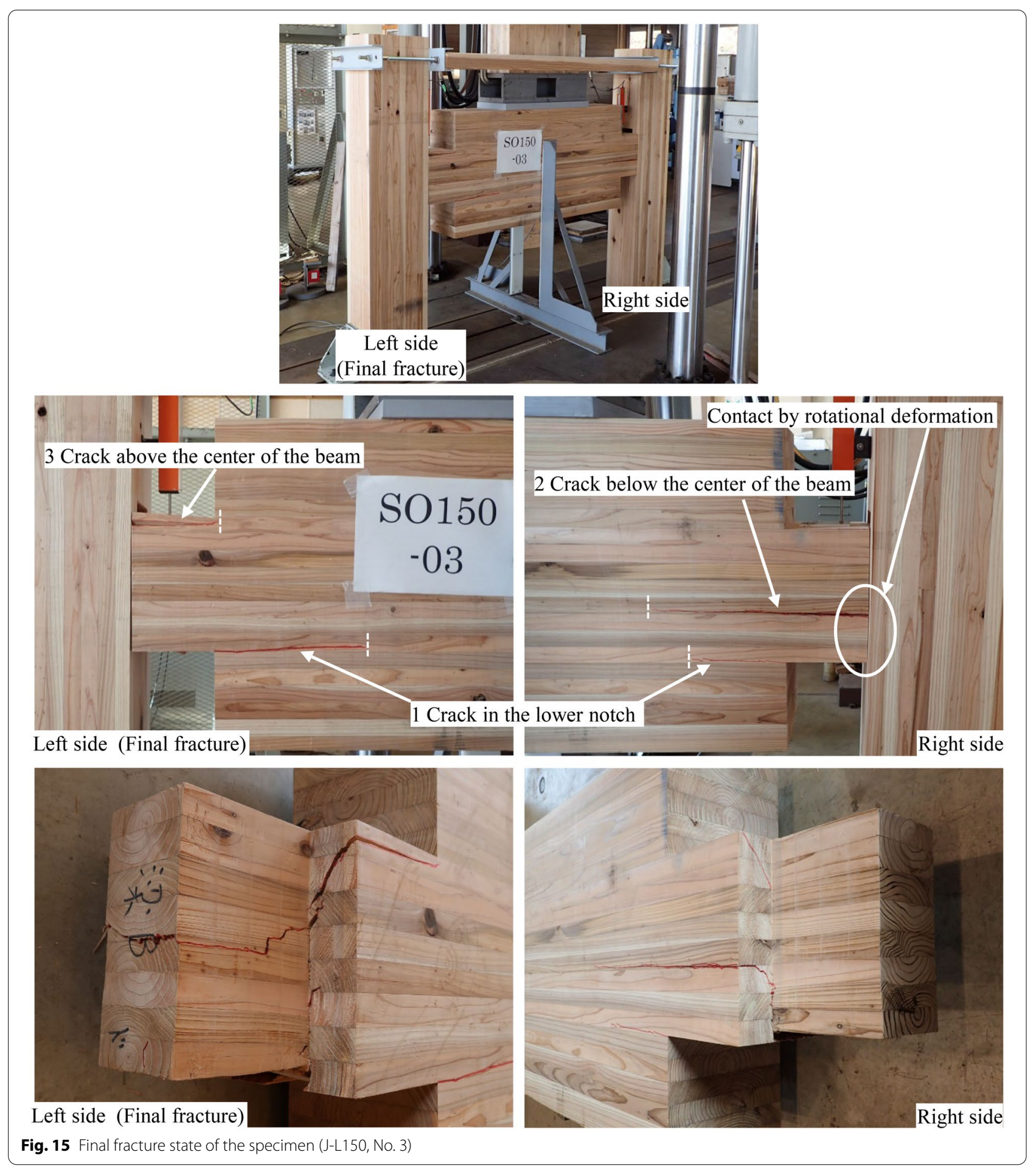




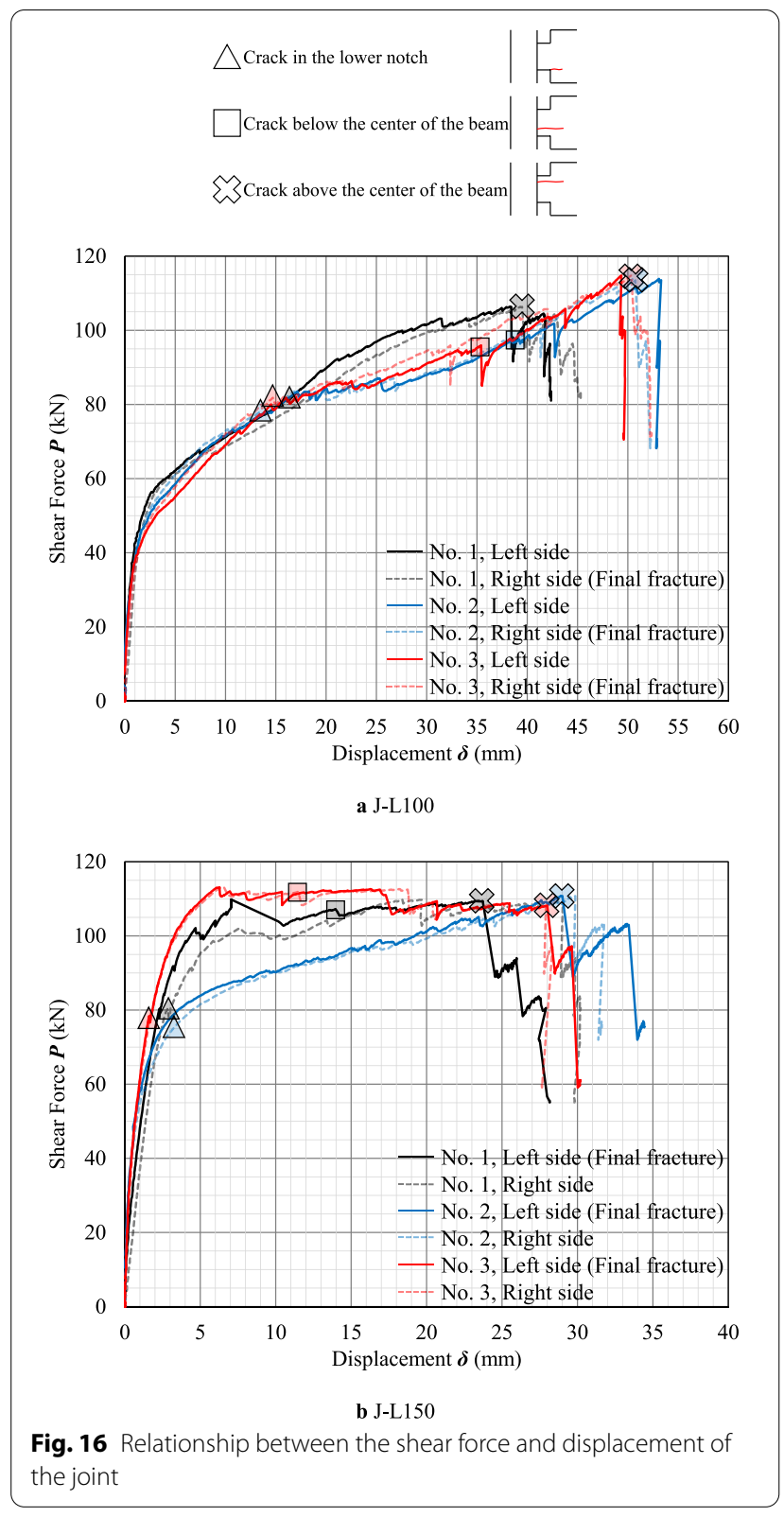

$P$ was significantly reduced. The crack above the center of the beam became a large crack as soon as it occurred. The fracture conditions in Figs. 10, 11, 12, 13, 14 and 15 indicate that the splitting fracture above the center of the beam is due to the shear force.

For J-L100, all the specimens showed the same $P-\delta$ relationship, and the displacements leading to final fracture were all in the approximate range of $40 \mathrm{~mm}$ to $50 \mathrm{~mm}$. For J-L150, only No. 2 showed a significant decrease in stiffness after cracking occurred at the lower notch, but the displacements leading to final fracture were all in the approximate range of $25 \mathrm{~mm}$ to $30 \mathrm{~mm}$.
In No.1 and No.3 of J-L150, half of the wood fibers on the surface of tenon were fractured (Fig. 17a), but in the other specimens, all wood fibers on the surface of the tenon were fractured (Fig. 17b). The shear force $P$ after the splitting fracture of No.1 and No.3 of J-L150 was high, although it is unclear whether this high shear force affected the results.

The concern with the experiment in Fig. 3 is the short distance from the force plate to the beam end. It is possible that the influence of the force plate restrains the fracture. First, we consider (1) a "crack in the lower notch". According to the finite element analysis results for notched beams [19], the load decreases as soon as the crack starts, and the load is approximately $1 / 2$ when the crack reaches the position shown in Fig. 18. Thereafter, the load increases as the crack lengthens due to the force plate. Therefore, we can expect that the load increases when the crack length is more than $90 \mathrm{~mm}$ in the experiment shown in Fig. 3. For J-L100, the crack length was less than $90 \mathrm{~mm}$, and for J-L150, the crack length was more than $90 \mathrm{~mm}$. Therefore, J-L150 may have suppressed the fracture due to the restraint of the force plate, but J-L100 is not considered to have suppressed the fracture due to the restraint of the force plate. Next, for a (2) "crack below the center of the beam", cracks occurred near the force plate in J-L100 (No. 2, No. 3) and J-L150 (No. 3), where this fracture occurred. There is a possibility that $P$ was reduced by this fracture, but this could not be confirmed in this study. Finally, for a (3) "crack above the center of the beam", it can be said that there is no effect due the force plate because the load was significantly reduced when the crack was identified.

\section{Compression performance perpendicular to the grain of the tenon}

Figure 19 shows the relationship between the force point load $F$ and displacement $\delta$ for $\mathrm{C}-\mathrm{H} 200$ (Fig. 8a) and J-L100 ( $L=100 \mathrm{~mm}$ in Fig. 3). $\delta$ in $\mathrm{C}-\mathrm{H} 200$ is the relative displacement between the force plate and the bottom surface of the specimen at the force point. $\delta$ in J-L100 is the relative displacement between the column and the end of the beam. The relationship between $F-\delta$ of $\mathrm{C}-\mathrm{H} 200$ and $\mathrm{J}$-L100 is almost identical up to around the yield point. The results show that compressive deformation perpendicular to the grain at the side of the tenon has a significant contribution on the deformation performance of J-L100. After the yield point, the rate of increase in load was larger for J-L100 than for $\mathrm{C}-\mathrm{H} 200$. The exact reason for this is unknown, but it may be due to the frictional resistance at the point where the beam end is in contact with the column due to rotational deformation. 
Table 1 Results of the evaluation using the elastic-perfectly plastic model

\begin{tabular}{|c|c|c|c|c|c|c|c|c|c|c|c|c|c|c|c|c|}
\hline & \multicolumn{8}{|l|}{ J-L100 } & \multicolumn{8}{|l|}{ J-L150 } \\
\hline & \multicolumn{4}{|c|}{ Left side } & \multicolumn{4}{|c|}{ Right side (final fracture) } & \multicolumn{4}{|c|}{ Left side (final fracture) } & \multicolumn{4}{|c|}{ Right side } \\
\hline & No.1 & No.2 & No.3 & Ave & No.1 & No.2 & No.3 & Ave & No.1 & No.2 & No.3 & Ave & No.1 & No.2 & No.3 & Ave \\
\hline (kN/mm) & & 24.29 & 22.85 & 23.94 & 20.82 & 23.76 & 17.95 & 20.84 & & 34.27 & 0.63 & 45.27 & 32.20 & 29.05 & 57.43 & 39.56 \\
\hline$P_{\max }(\mathrm{kN})$ & 101.56 & 87.95 & 91.02 & 93.51 & 99.52 & 88.48 & 94.37 & 94.13 & 109.71 & 110.78 & 113.03 & 111.17 & 109.73 & 110.75 & 113.05 & 111.18 \\
\hline$P_{y}(\mathrm{kN})$ & 53.23 & 47.29 & 44.93 & 48.49 & 54.00 & 49.22 & 50.55 & 51.26 & 64.83 & 72.27 & 62.54 & 66.55 & 71.03 & 70.21 & 62.70 & 67.98 \\
\hline$P_{\mathrm{u}}(\mathrm{kN})$ & 82.94 & 77.53 & 77.17 & 79.21 & 80.18 & 78.10 & 80.57 & 79.62 & 106.03 & 97.55 & 108.23 & 103.94 & 103.57 & 97.31 & 108.91 & 103.26 \\
\hline$P_{\delta=1 \mathrm{~mm}}(\mathrm{kN})$ & 41.89 & 37.71 & 37.66 & 39.08 & 34.21 & 38.81 & 35.54 & 36.18 & 48.24 & 58.66 & 61.37 & 56.09 & 37.16 & 54.74 & 59.66 & 50.52 \\
\hline$P_{\delta=2 \mathrm{~mm}}(\mathrm{kN})$ & 52.46 & 47.59 & 45.14 & 48.39 & 49.59 & 48.64 & 45.89 & 48.04 & 74.68 & 71.20 & 83.94 & 76.61 & 66.62 & 66.76 & 83.37 & 72.25 \\
\hline$P_{\delta=3 \mathrm{~mm}}(\mathrm{kN})$ & 57.37 & 52.75 & 49.65 & 53.26 & 56.24 & 54.02 & 51.26 & 53.84 & 89.49 & 77.72 & 97.17 & 88.13 & 79.09 & 73.82 & 96.62 & 83.18 \\
\hline$P_{\delta=4 \mathrm{~mm}}(\mathrm{kN})$ & 59.84 & 55.60 & 52.45 & 55.96 & 59.24 & 57.79 & 54.35 & 57.13 & 98.39 & 81.45 & 105.03 & 94.96 & 89.04 & 78.28 & 104.11 & 90.48 \\
\hline$P_{\delta=5 \mathrm{~mm}}(\mathrm{kN})$ & 62.12 & 58.54 & 55.11 & 58.59 & 61.26 & 61.02 & 57.75 & 60.01 & 100.07 & 83.85 & 109.27 & 97.73 & 95.25 & 81.55 & 108.43 & 95.07 \\
\hline$\delta_{P_{\max }}(\mathrm{mm})$ & 29.80 & 30.00 & 30.00 & 29.93 & 30.00 & 29.90 & 30.00 & 29.97 & 7.10 & 28.90 & 6.20 & 14.07 & 19.50 & 29.80 & 6.50 & 18.60 \\
\hline$\delta_{y}(\mathrm{~mm})$ & 2.16 & 1.95 & 1.97 & 2.02 & 2.59 & 2.07 & 2.82 & 2.49 & 1.58 & 2.11 & 1.03 & 1.58 & 2.21 & 2.42 & 1.09 & 1.90 \\
\hline$\delta_{v}(\mathrm{~mm})$ & 3.36 & 3.19 & 3.38 & 3.31 & 3.85 & 3.29 & 4.49 & 3.88 & 2.59 & 2.85 & 1.78 & 2.41 & 3.22 & 3.35 & 1.90 & 2.82 \\
\hline$\delta_{u}(\mathrm{~mm})$ & 30.00 & 30.00 & 30.00 & 30.00 & 30.00 & 30.00 & 30.00 & 30.00 & 26.10 & 30.00 & 29.60 & 28.57 & 29.80 & 30.00 & 28.30 & 29.37 \\
\hline
\end{tabular}

$K$ : elastic stiffness, $P_{\max }:$ maximum shear strength, $P_{\mathrm{y}}$ : yield shear strength, $P_{\mathrm{u}}$ : ultimate shear strength, $P_{\delta=1 \mathrm{~mm}}$ : shear strength at a displacement of $1 \mathrm{~mm}, P_{\delta=2 \mathrm{~mm}}$ : shear strength at a displacement of $2 \mathrm{~mm}, P_{\delta=3 \mathrm{~mm}}$ : shear strength at a displacement of $3 \mathrm{~mm}, P_{\delta=4 \mathrm{~mm}}$ : shear strength at a displacement of $4 \mathrm{~mm}, P_{\delta=5 \mathrm{~mm}}$ : shear strength at a displacement of $5 \mathrm{~mm}, \delta_{P_{\max }}$ : displacement at the maximum shear strength, $\delta_{\mathrm{y}}:$ yield displacement, $\delta_{\mathrm{v}}: P_{\mathrm{u}} / K$, and $\delta_{\mathrm{u}}:$ ultimate displacement

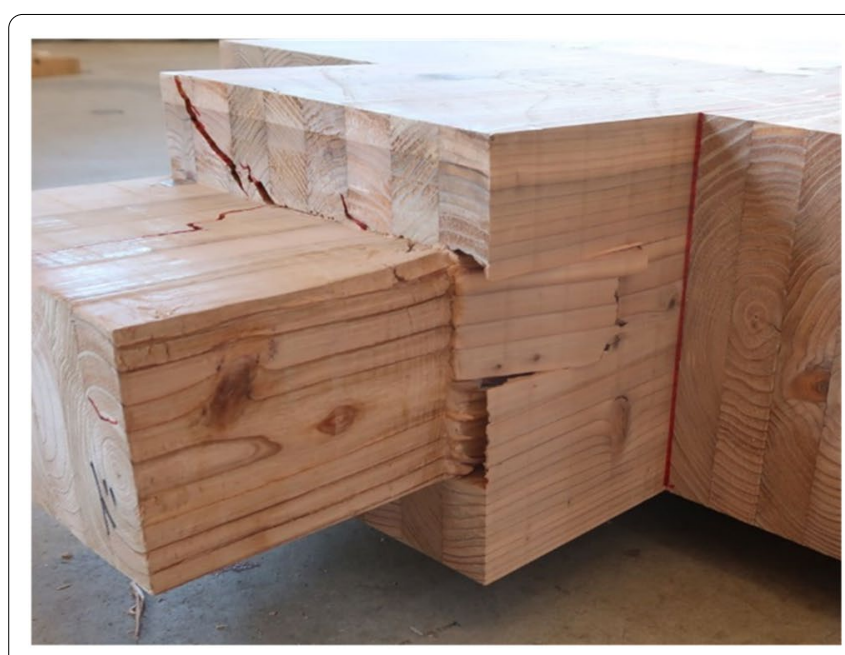

a L150, No. 1 and L150, No. 3

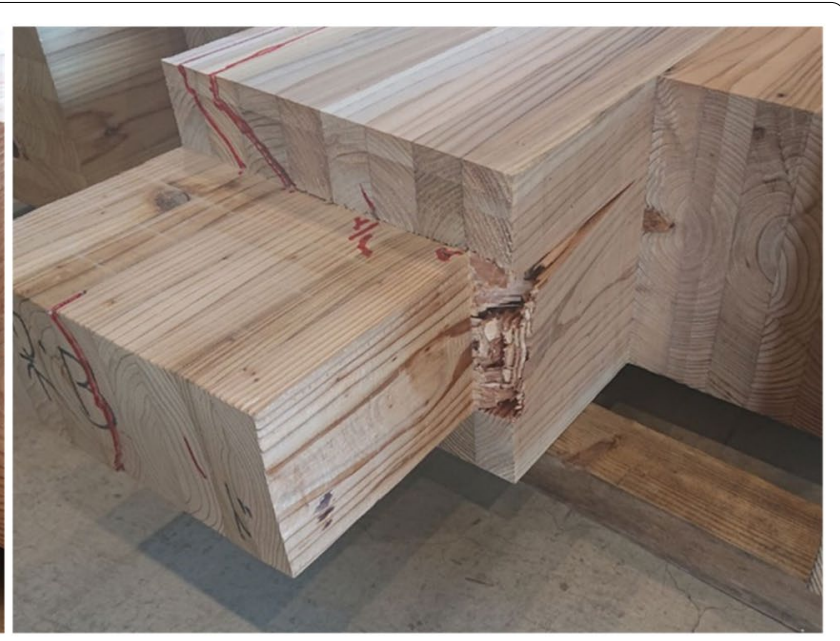

b Other Specimens

Fig. 17 Fracture of the tenon

Figure 20 shows the relationship between the force point load $F$ and displacement $\delta$ for $\mathrm{C}-\mathrm{H} 200$ (Fig. 8a) and $\mathrm{C}$-I200 (Fig. $8 \mathrm{~b}$ ). $\delta$ is the relative displacement between the force plate and the bottom surface of the specimen at the force point. The widths of the force surface are slightly different for various specimens, namely, $105 \mathrm{~mm}$ for C-H200 and $100 \mathrm{~mm}$ for C-I200, so $F$ of C-I200 is multiplied by 1.05 to make CI200 comparable to $\mathrm{C}-\mathrm{H} 200$. The ratio of the average values of $P(\mathrm{C}-\mathrm{H} 200 / \mathrm{C}-\mathrm{I} 200)$ is
1.48 for $\delta=2 \mathrm{~mm}$ and 1.47 for $\delta=4 \mathrm{~mm}$, demonstrating a large difference in load due to the difference in the extra length portion.

Figure 21 shows the relationship between the force point load $F$ and displacement $\delta$ for C-I200 (Fig. 8b) and C-200 (Fig. 8d), and Fig. 22 shows the relationship between the force point load $F$ and displacement $\delta$ for $\mathrm{C}-\mathrm{I} 300$ (Fig. 8c) and C-300 (Fig. 8e). $\delta$ is the relative 


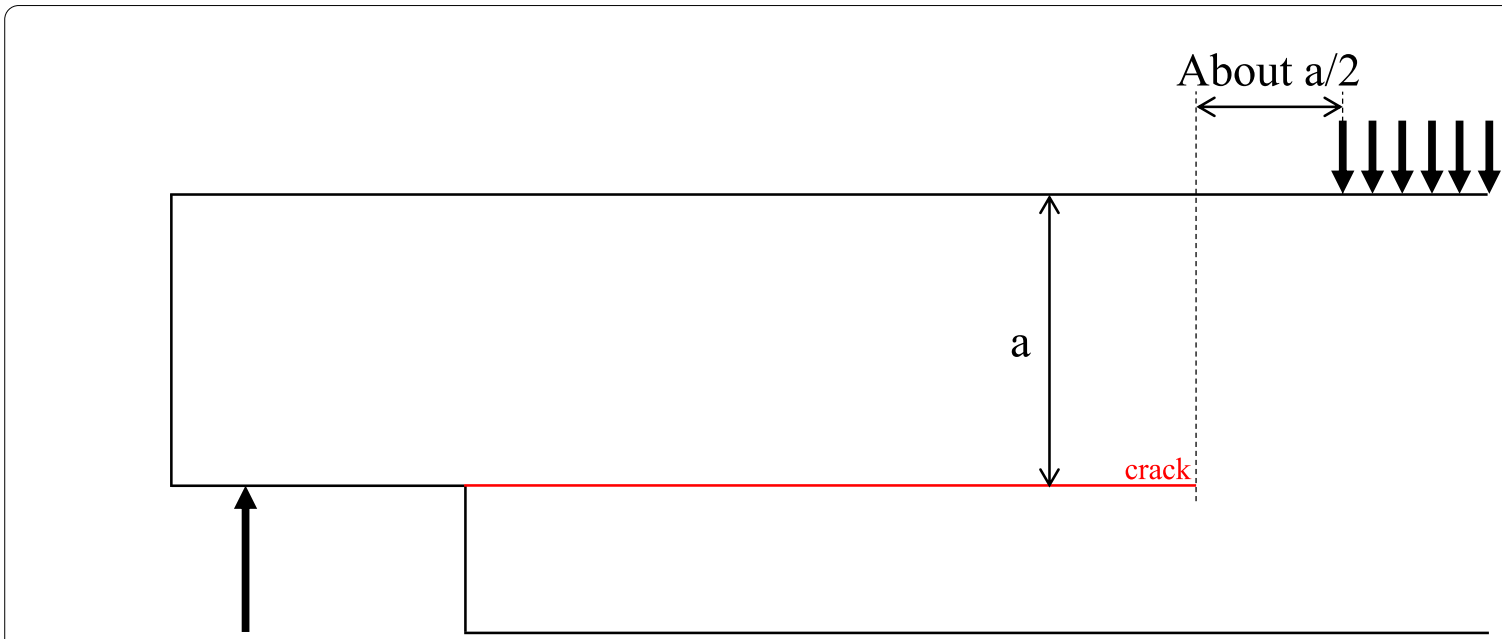

Fig. 18 Crack length at which the load is reduced

displacement between the force plate and the bottom surface of the specimen at the force point. C-I300 finally fractured in bending or shear. Although the specimen heights of C-200 and C-300 are half of those of C-I200 and C-I300, the $F-\delta$ relationships are almost identical.

No experiment was conducted for $\mathrm{C}-\mathrm{H} 200$ with an applied force length of $300 \mathrm{~mm}$ (C-H300), so the load $F_{\mathrm{C}-\mathrm{H} 300 \text { (cal.) }}$ for each displacement $\delta$ was estimated using Eq. (6):

$$
F_{\mathrm{C}-\mathrm{H} 300}(\text { cal. })=F_{\mathrm{C}-\mathrm{H} 200}+1.05 \cdot\left(F_{\mathrm{C}-\mathrm{I} 300}-F_{\mathrm{C}-\mathrm{I} 200}\right) \text {, }
$$

where $F_{\mathrm{C}-\mathrm{H} 200}$ is the average value of load $F$ for C-H200, $F_{\mathrm{C}-\mathrm{I} 200}$ is the average value of load $F$ for C-I200, and $F_{\mathrm{C}-}$ I300 is the average value of load $F$ for C-I300. The coefficient for transforming the width from 100 to $105 \mathrm{~mm}$ is 1.05 .

Figure 23 shows the relationship between the force point load $F$ and displacement $\delta$ for $\mathrm{C}-\mathrm{H} 300$ (cal.) and $\mathrm{J}$-L150 ( $L=150 \mathrm{~mm}$ in Fig. 3$). \delta$ for J-L150 is the relative displacement between the column and the end of the beam. The relationships between $F-\delta$ of C-H300 (cal.) and J-L150 No. 2 are almost identical until reaching the yield point. This result shows that compressive deformation perpendicular to the grain at the side of the tenon has a significant contribution to the deformation performance of J-L150 and J-L100.

The $F-\delta$ relationship for $\mathrm{C}-200$ and $\mathrm{C}-300$ can be obtained using the formula for the compressive performance perpendicular to the grain [20]. Therefore, C-I200 and C-I300, which have approximately identical performance to C-200 and C-300, can be estimated. Although we expected the performance of $\mathrm{C}-\mathrm{H} 200, \mathrm{C}-\mathrm{H} 300$ (cal.) and $\mathrm{C}-200$ and $\mathrm{C}-300$ to be generally identical, the difference in bearing capacity that we could confirm in our experiments was very large. The formula for compressive performance perpendicular to the grain of the wood [20] does not give the performance for unique shapes such as $\mathrm{C}-\mathrm{H} 200$ and $\mathrm{C}-\mathrm{H} 300$ (cal.). A future method should be proposed to estimate the compressive performance perpendicular to the grain of the wood for unique shapes such as the side of a tenon.

\section{Splitting strength of the beam at the notch}

The relationship between the mode 1 fracture energy $G_{\mathrm{c}}$ and density $\rho$ obtained from the experiment in Fig. 6 is shown in Fig. 24. Additionally, Eq. (7) [21] for the relationship between $G_{\mathrm{c}}$ and $\rho$ for Nordic redwood is included in Fig. 24:

$$
G_{\mathrm{c}}\left(\mathrm{N} \mathrm{m} / \mathrm{m}^{2}\right)=1.07 \times \rho\left(\mathrm{kg} / \mathrm{m}^{3}\right)-162 .
$$

The experimental values of $G_{c}$ for the specimen with the notch in the center of the lamina and the specimen with the notch in the adhesive layer were almost identical. Therefore, the calculation can be performed without changing the value of $G_{c}$, whether splitting fracture occurs in the center of the lamina or near the adhesive layer. It was also confirmed that Eq. (7) yielded approximately identical values to the average experimental values.

The average value of $G_{\mathrm{c}}\left(G_{\mathrm{c}}=279 \mathrm{~N} \mathrm{~m} / \mathrm{m}^{2}\right)$ is used to obtain the splitting strength by Eq. (5). $E_{x}$ and $G_{x y}$ in Eq. (5) are the values of the interval $D \Delta \beta$ in Figs. $6 \mathrm{c}$ and 7. The cross-sectional configuration is shown in Fig. 25, and the equivalent Young's modulus, which is the bending stiffness of this section divided by the moment of 

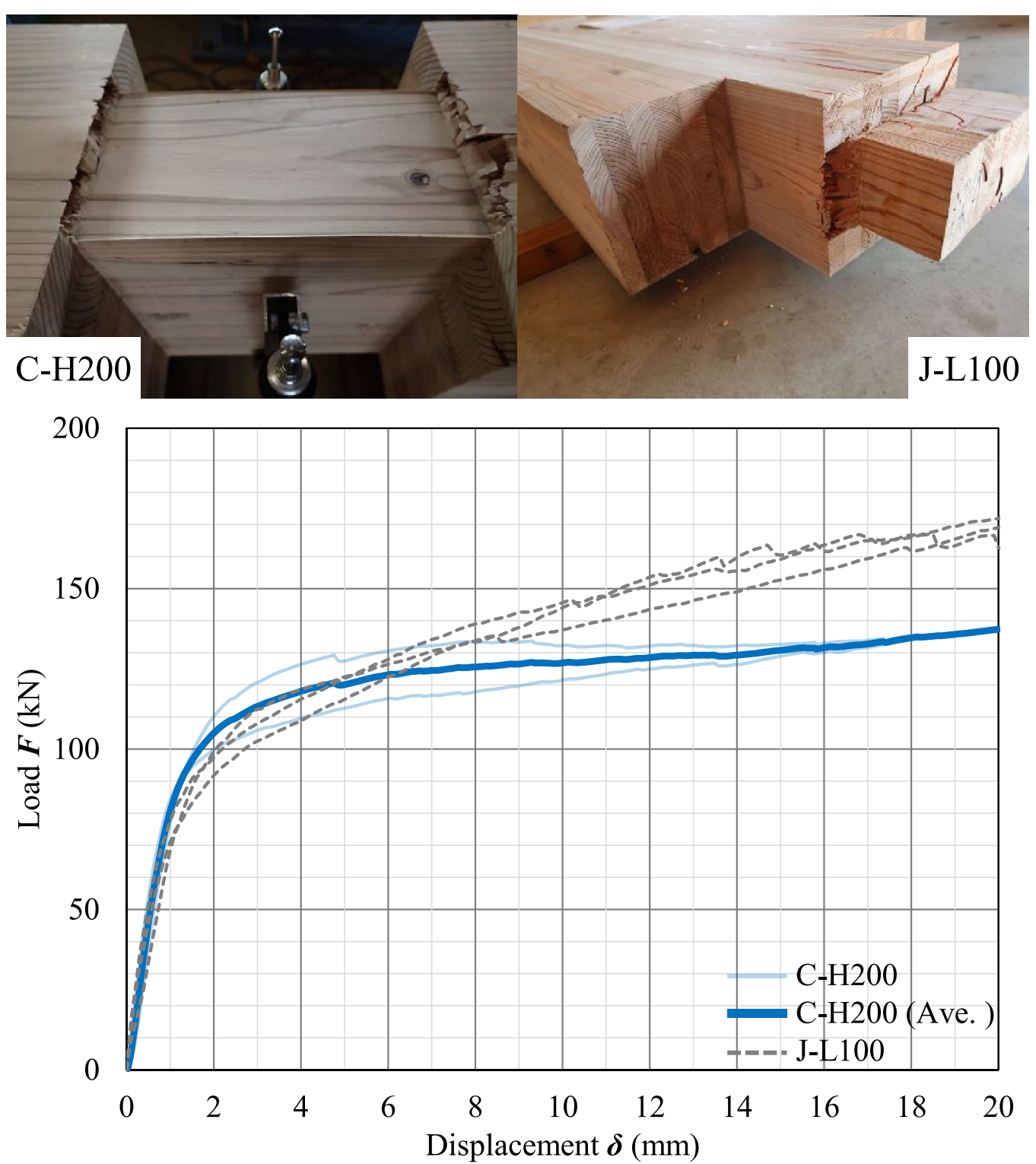

Fig. 19 Relationship between the force point load F and displacement $\delta$ of C-H200 and J-L100

inertia, is $E_{x}=5368 \mathrm{~N} / \mathrm{mm}^{2}$. All the notched sections at the beam end are the inner lamina (L40). Therefore, these values were used, assuming that the Young's modulus ranges from $E_{x}=4000 \mathrm{~N} / \mathrm{mm}^{2}$ (the value for inner lamina L40 given in Japanese Agricultural Standard [12]) to $E_{x}=5368 \mathrm{~N} / \mathrm{mm}^{2}$. The shear modulus is set to $G_{x y}=E_{x} / 15$ [20]. The exact location of $P$ and $M$ acting on the end of the beam is unknown. Figures 10, 11, 12, 13,14 and 15 show that the side of the tenon is deformed to some extent with equal displacement. Therefore, it was assumed that $P$ and $M$ acting on the beam end acted at the center position of the tenon $(D \beta=200 \mathrm{~mm}$ for J-L100 and $D \beta=225 \mathrm{~mm}$ for J-L150 in Fig. 6c). The $M / P$ values are $0 \mathrm{~mm}$ and $250 \mathrm{~mm}$ for $\mathrm{J}-\mathrm{L} 100$ and $0 \mathrm{~mm}$ and $262.5 \mathrm{~mm}$ for J-L150. When the beam end does not resist the bending moment, $M / P$ is $0 \mathrm{~mm}$; when the beam end is rigidly connected and the bending moments at the beam end and the force plate end are identical, $M / P$ is $250 \mathrm{~mm}$ and $262.5 \mathrm{~mm}$. In addition, the values of $D \beta$ in Fig. 7 were varied to obtain the splitting strength for crack lengths of $0-100 \mathrm{~mm}$.

The comparison between the experimental values and the calculated values of the splitting strength and the relationship between the calculated values of the splitting 

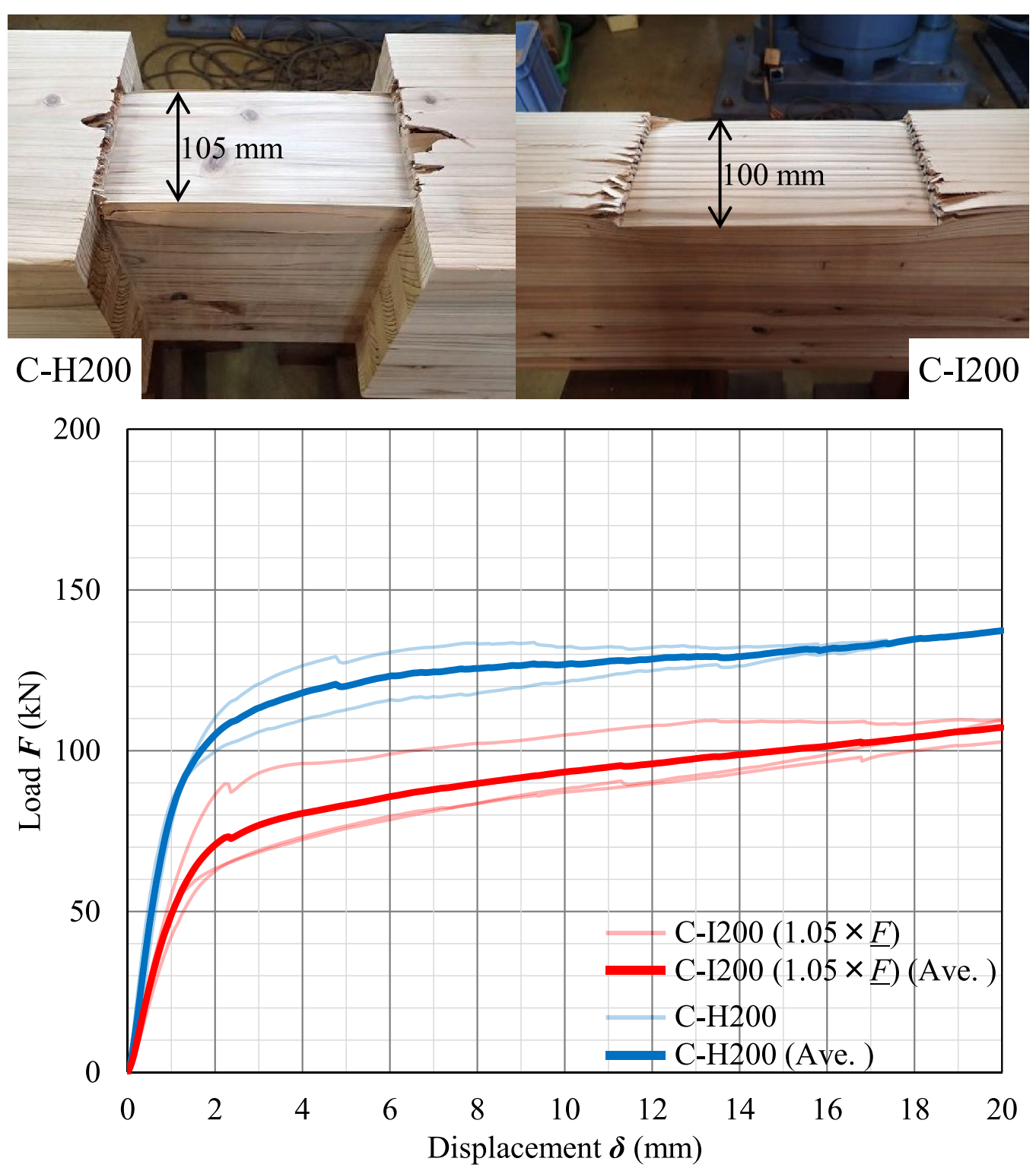

Fig. 20 Relationship between the force point load $F$ and displacement $\delta$ of C-H200 and C-I200

strength and crack length are shown in Figs. 26, 27. The calculated splitting strengths of both J-L100 and J-L150 when $M / P=0 \mathrm{~mm}$ were approximately identical to the shear force when the splitting fracture was visually identified. In addition, the calculated values of the splitting strength for both J-L100 and J-L150 when $M / P=250 \mathrm{~mm}$ or $262.5 \mathrm{~mm}$ were approximately equal to the maximum strength. The splitting strength after crack initiation decreased little by little as the crack length increases. However, experiments showed that the crack length gradually increased as the load gradually increased after crack initiation. These results suggest that the lower notch crack with the beam end barely resisted the bending moment, and the bearing capacity did not decrease because the degree of fixation of the beam end increased when the deformation progressed. However, since the distance from the force plate to the crack was short for J-L150, if the distance from the force plate to the crack increased, the bearing capacity might decrease before reaching the maximum bearing capacity of the experimental value.

The mortise and tenon joints of the specimen shown in Fig. 3 were machined with very high precision, and special tools were used for assembly. When used in a 

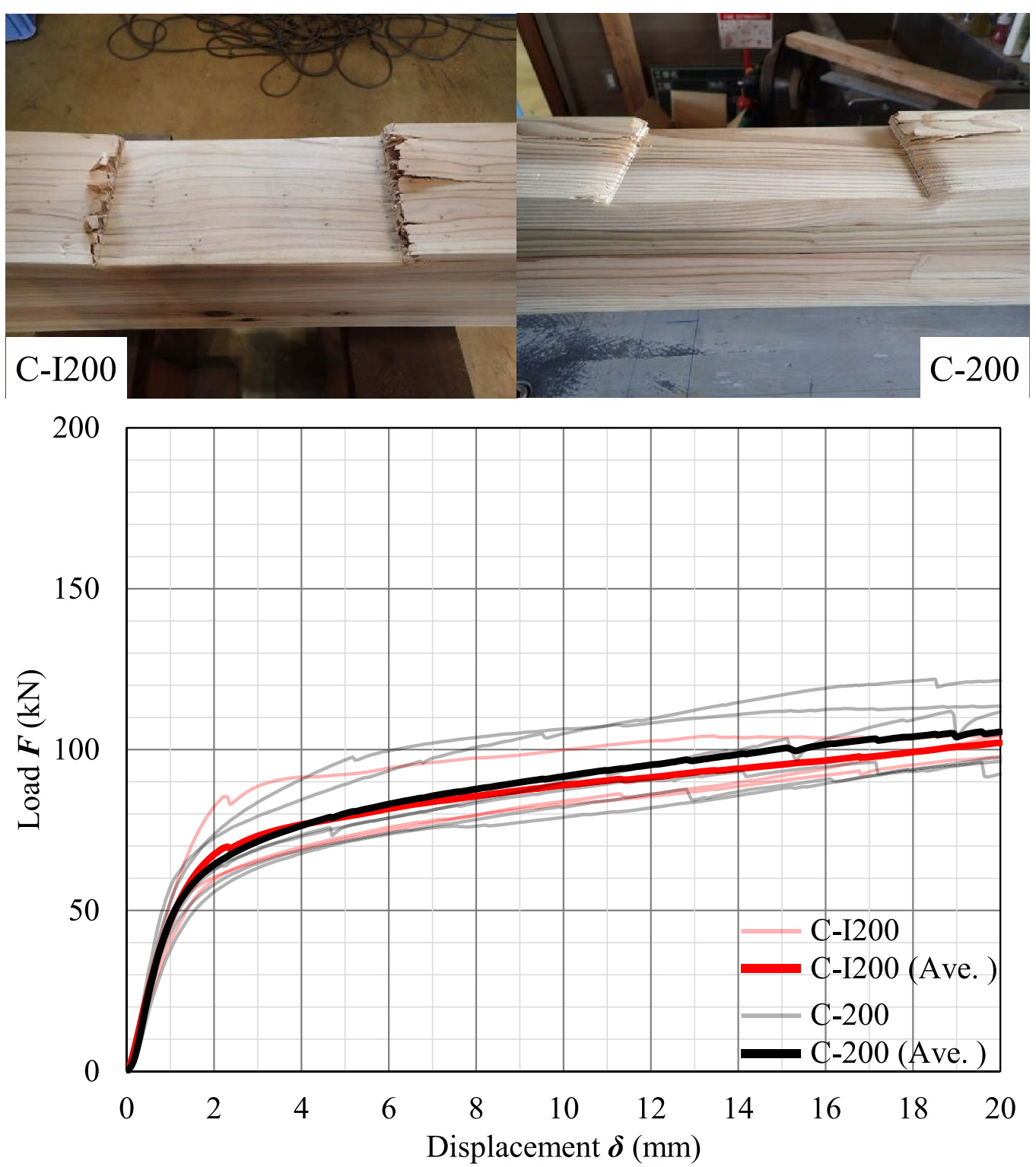

Fig. 21 Relationship between the force point load $F$ and displacement $\delta$ of C-1200 and C-200

building, the degree of fixation at the end may be smaller than that of the specimen shown here. Therefore, the bearing capacity of the joints should be designed with the assumption that the beam ends have very little bending resistance.

\section{Shear strength of the beam end}

The final fracture mode of a mortise and tenon joint is splitting fracture by shear force. In this specimen, the joint can be safely used in buildings as long as the resistance values to compression failure perpendicular to the grain on the side of the mortise (Fig. 2a) and to splitting fracture at the notch (Fig. 2b) are known. In addition, the severe damage to the tenon makes it is difficult to estimate the maximum bearing capacity from the shear strength of the wood. For these reasons, we did not conduct any experiments to determine the shear strength of wood. However, an estimation of the bearing capacity using a simple study will be useful when calculating this maximum bearing capacity, so we decided to conduct a simple study using the existing experimental data [22].

The beam end experienced a significant reduction in bearing capacity due to the splitting fracture by the shear force of the tenon (Figs. 10, 11, 12, 13, 14 and 15). 

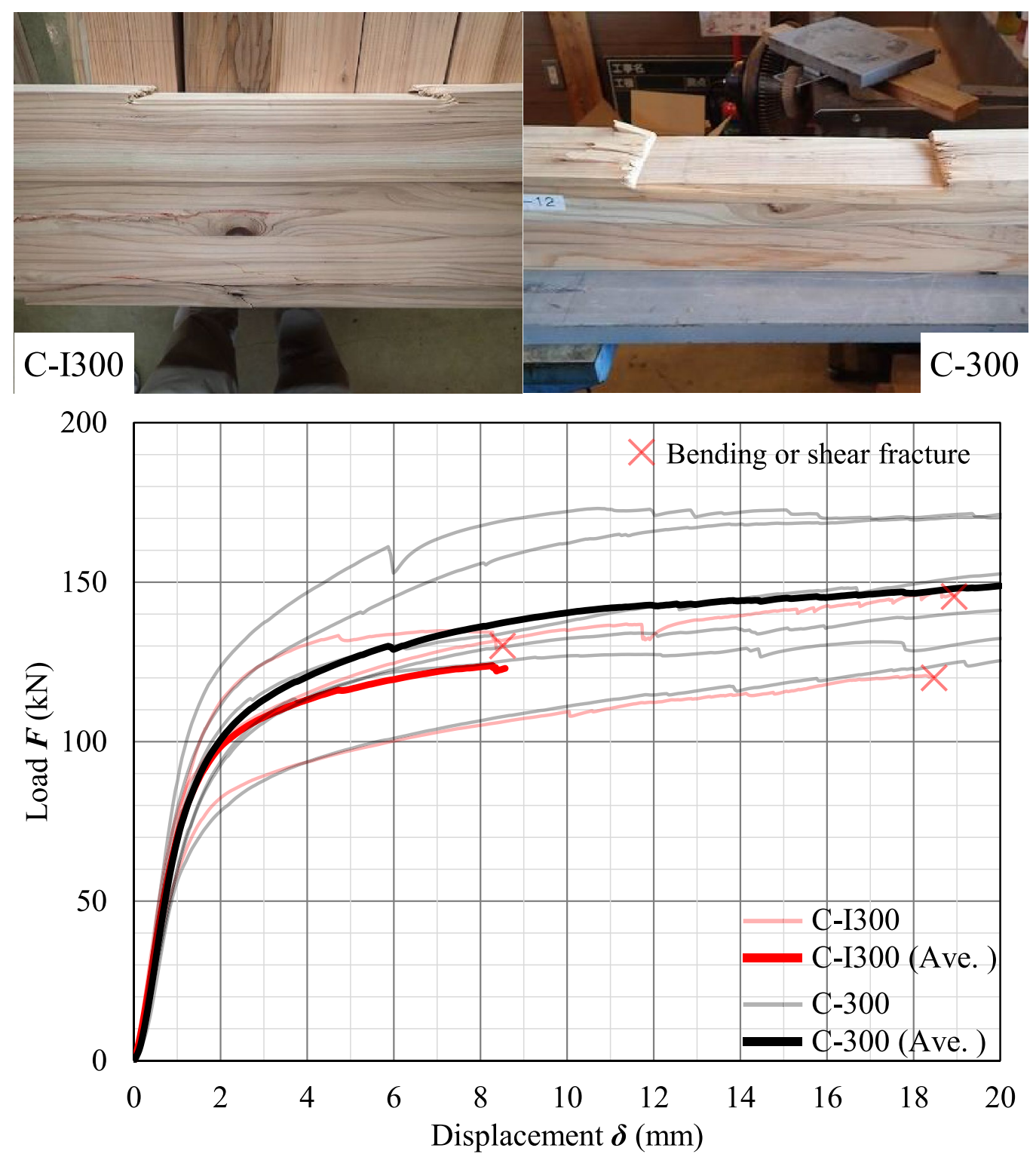

Fig. 22 Relationship between the force point load $F$ and displacement $\delta$ of C-1300 and C-300

Therefore, the maximum bearing capacity $P_{\max }$ is estimated from the cross-sectional area and shear strength of the tenon using Eq. (8):

$$
P_{\max }=F_{\mathrm{s}} \times A / 1.5,
$$

where $F_{\mathrm{s}}$ is the shear strength of the tenon (inner lamina L40). $A$ is the cross-sectional area of the tenon $(105 \mathrm{~mm} \times 240 \mathrm{~mm})$.
$F_{\mathrm{s}}$ used in Eq. (8) is based on existing experimental data [22] obtained from the test methods of JIS Z 2101 [23] and ISO 13910 [24]. The existing experimental data [22] are $F_{\mathrm{s}}$ of the inner lamina L40 of glued laminated timber composed of mixed-grade laminae (symmetrical composition with a strength grade of E65-F225) for Japanese cedar (Cryptomeria japonica). The $F_{\mathrm{s}}$ values obtained by the JIS Z 2101 test method [23] are 


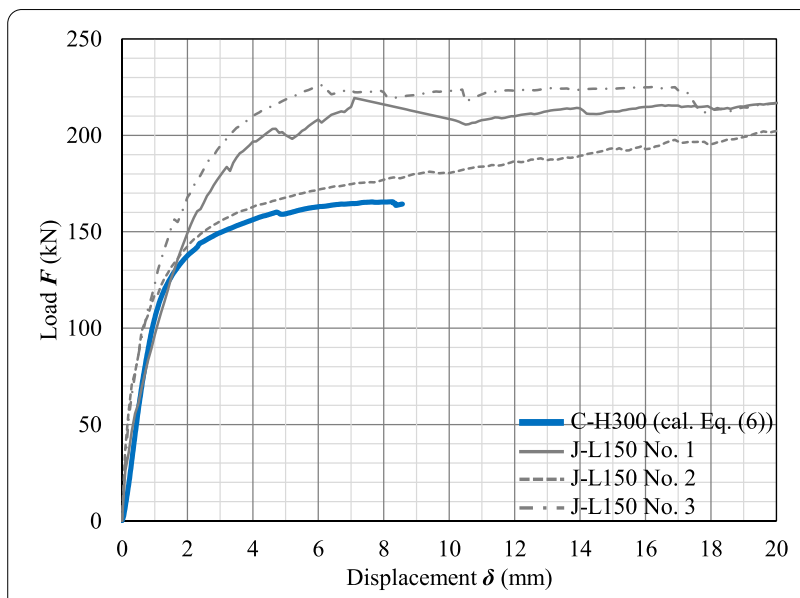

Fig. 23 Relationship between the force point load $F$ and displacement $\delta$ of C-H300 (Cal.) and J-L150

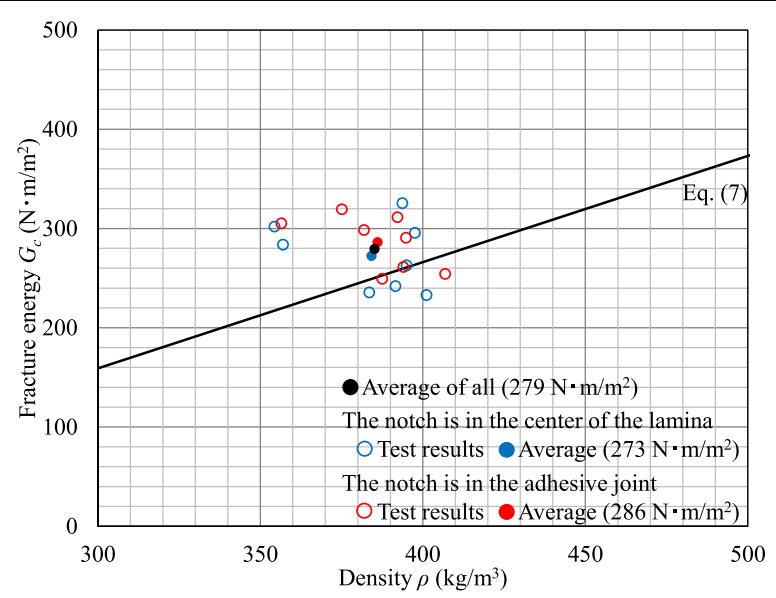

Fig. 24 Mode I fracture energy $G_{c}$

$F_{\mathrm{s}}=9.4 \mathrm{~N} / \mathrm{mm}^{2}$ (average value of 30 specimens where the average value of the density is $405 \mathrm{~kg} / \mathrm{m}^{3}$ ) for the test with a $25 \mathrm{~mm} \times 25 \mathrm{~mm}$ shear plane and $F_{\mathrm{s}}=7.7 \mathrm{~N} /$ $\mathrm{mm}^{2}$ (average value of 30 specimens where the average value of the density is $423 \mathrm{~kg} / \mathrm{m}^{3}$ ) for the test with a $120 \mathrm{~mm} \times 120 \mathrm{~mm}$ shear plane. The value of $F_{\mathrm{s}}$ obtained

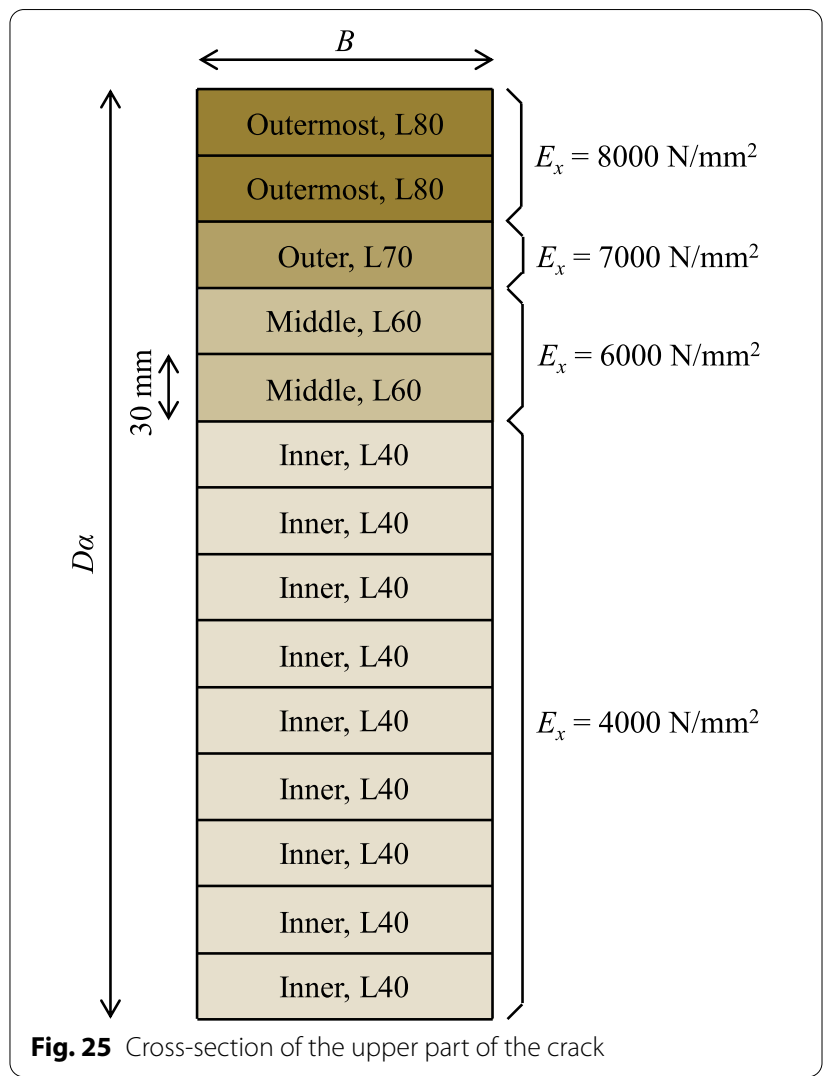

by the test method of ISO 13910 [24] is $F_{\mathrm{s}}=7.2 \mathrm{~N} / \mathrm{mm}^{2}$ (average value of 30 specimens where the average value of the density is $424 \mathrm{~kg} / \mathrm{m}^{3}$ ) for a three-point bending test with a span of $600 \mathrm{~mm}$, specimen width of $120 \mathrm{~mm}$, and specimen height of $150 \mathrm{~mm}$.

The comparison between the experimental values and the calculated values of the maximum bearing capacity is shown in Fig. 28. Although the value of $F_{\mathrm{s}}$ differs depending on the test method, the calculated value is slightly or significantly higher than the experimental value, possibly since the stress bias caused by the force acting from the side of the tenon and the severe damage at the beam end resulted in a lower bearing capacity at shear fracture.

\section{Conclusion}

In this study, shear experiments were performed on mortise and tenon joints with top and bottom notches at the beam end. Then, material experiments were conducted to investigate the structural performance of the fracture 


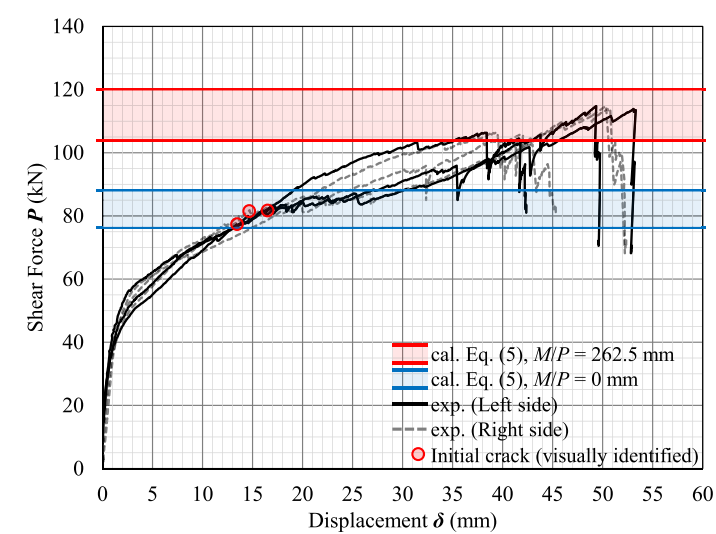

a Experimental values vs. calculated splitting strength (the crack length is $0 \mathrm{~mm}$ )

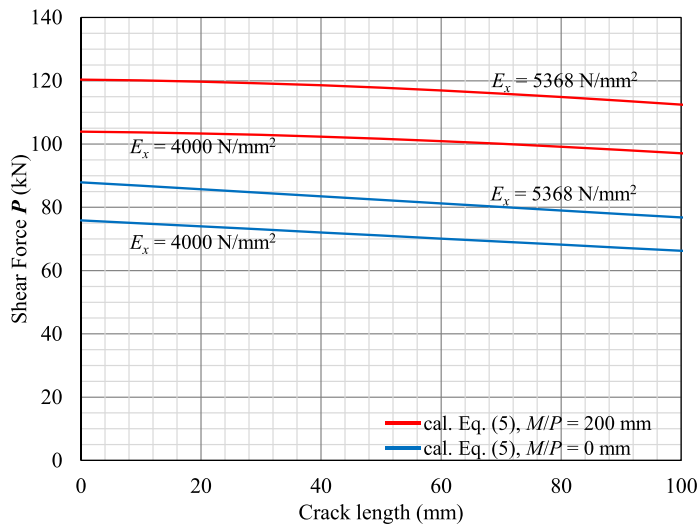

b Relationship between the calculated values of the splitting strength and crack length

Fig. 26 Calculated value of the splitting strength for J-L100

mode of the joint and clarify the shear performance of the joint. The following results were obtained:

1. The shear force at the splitting fracture at the lower notch was identical for different lengths of the tenon. In addition, it was confirmed that the shear force that caused the splitting fracture of the lower notch could be approximately estimated by the calculated splitting strength when the beam end did not resist the moment.

2. The shear force increased without decreasing even when the lower notch splitting fractured. One reason is that the degree of fixation at the beam end increased with rotational deformation.

3. The deformation performance of the joint until yielding was largely due to the compressive deformation perpendicular to the grain on the side of the tenon.

4. The final fracture of the joint was a shear fracture, but the bearing capacity was lower than the shear capacity of the tenon, which was estimated from the shear strength of the wood.

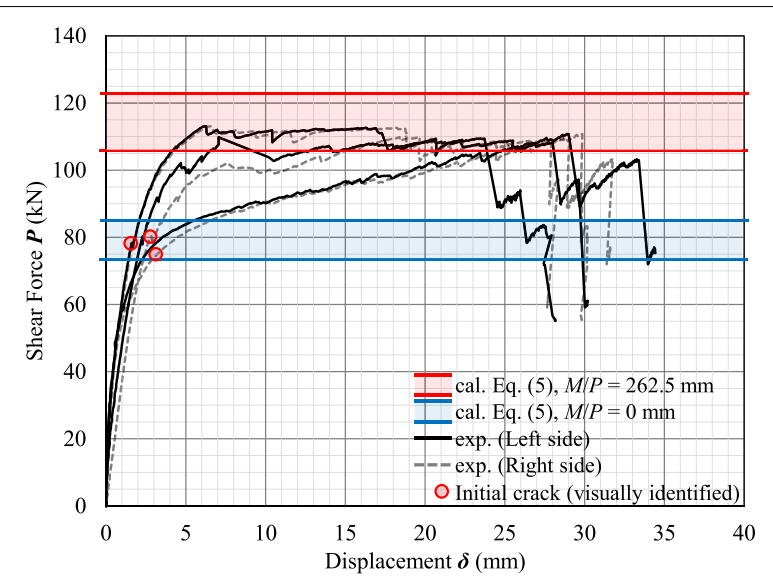

a Experimental values vs. calculated splitting strength (the crack length is $0 \mathrm{~mm}$ )

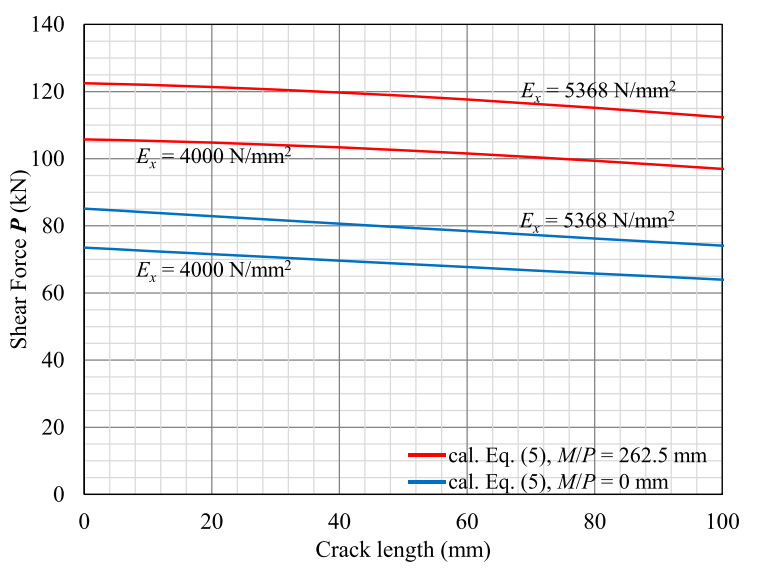

b Relationship between calculated values of split strength and crack length

Fig. 27 Calculated value of the splitting strength for J-L150

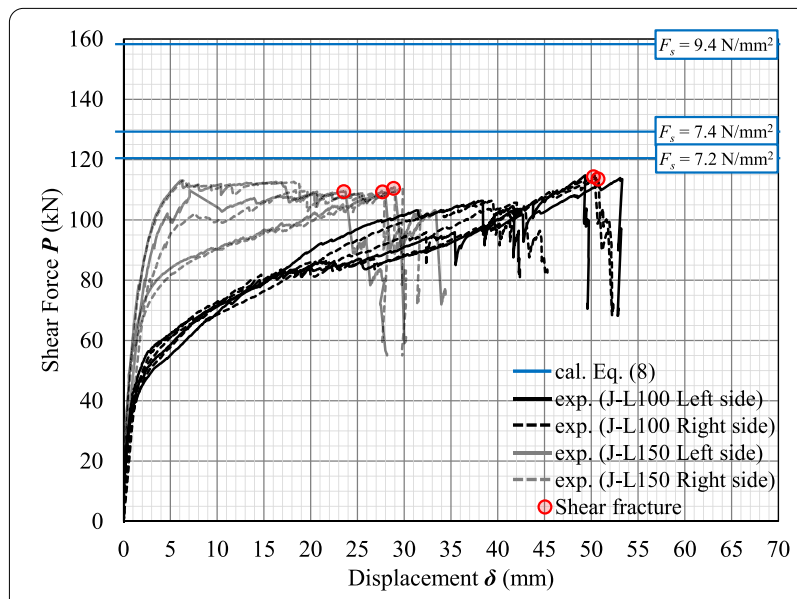

Fig. 28 Calculated shear strength vs. experimental values 


\section{Acknowledgements}

We would like to thank American Journal Experts (https://www.aje.com/) for proofreading this manuscript.

\section{Authors' contributions}

All authors designed the experiments. MN performed the experiments. SO analyzed the data and wrote the manuscript. All authors analyzed the results. All authors read and approved the final manuscript.

\section{Funding}

This work was supported as a part of the Forestry Agency's subsidized project (the first year of the Reiwa period) due to Dot Corporation Co. Ltd. and team Timberize non-profit organization.

\section{Availability of data and materials}

All data generated or analyzed during this study are included in this published article.

\section{Declarations}

\section{Competing interests}

The authors declare that they have no competing interests regarding the publication of this manuscript.

\section{Author details}

'Graduate School of Human Life Science, Osaka City University, 3-3-138 Sugimoto, Sumiyoshi-ku, Osaka 558-8585, Japan. ${ }^{2}$ Miyazaki Prefectural Wood Utilization Research Center, Hanaguricho, Miyakonojo 885-0037, Japan. ${ }^{3}$ National Institute for Land and Infrastructure Management, Tachihara, Tsukuba 305-0802, Japan. ${ }^{4}$ Faculty of Science and Technology, Oita University, Dannoharu, Oita 870-1192, Japan. ${ }^{5}$ Graduate School of Advanced Science and Engineering, Hiroshima University, Kagamiyama, Higashi-Hiroshima 739-8527, Japan.

Received: 16 March 2021 Accepted: 27 June 2021

Published online: 01 July 2021

\section{References}

1. Architectural Institute of Japan (2009) Design manual for engineered timber joints. Maruzen, Tokyo (in Japanese)

2. Mori T, Nakatani M, Tesfamariam S (2015) Performance of semirigid timber frame with Lagscrewbolt connections: experimental, analytical, and numerical model results. Int J Adv Struct Eng 7:387-403. https://doi.org/ 10.1007/s40091-015-0107-4

3. Tlustochowicz G, Serrano E, Steiger R (2011) State-of-the-art review on timber connections with glued-in steel rods. Mater Struct 44:997-1020. https://doi.org/10.1617/s11527-010-9682-9

4. Judd JP, Fonseca FS, Walker CR, Thorley PR (2012) Tensile strength of varied-angle mortise and tenon connections in timber frames. J Structural 138(5):636-644. https://doi.org/10.1061/(ASCE)ST.1943-541X.00004 68

5. Nakazono M, Hiroshima N, Bonkobara K, Inai E, Takami K, Kawahara R (2007) Tensile behavior of column base joint by nagahozosashi-komisen on traditional wooden structure. AIJ J Technol Des 13(25):119-124. https://doi.org/10.3130/aijt.13.119

6. Ogawa K, Sasaki Y, Yamasaki M (2016) Theoretical estimation of the mechanical performance of traditional mortise-tenon joint involving a gap. J Wood Sci 62:242-250. https://doi.org/10.1007/s10086-016-1544-9

7. Erdil YZ, Kasal A, Eckelman CA (2005) Bending moment capacity of rectangular mortise and tenon furniture joints. For Prod J 55(12):209-213

8. Gamerro J, Bocquet JF, Weinand $Y$ (2020) Experimental investigations on the load-carrying capacity of digitally produced wood-wood connections. Eng Struct 213:110576. https://doi.org/10.1016/j.engstruct.2020. 110576

9. Tsukazaki H, Kawai N, Komatsu Y, Fujino E, Maekawa H, Matsudome S (2015) Studies on shear strength properties of dovetails joint machined with precut system-studies of design formula based on failure types. J
Struct Constr Eng (Trans AIJ) 80(708):285-295. https://doi.org/10.3130/ aijs.80.285 (in Japanese)

10. Koch H, Eisenhut L, Seim W (2013) Multi-mode failure of form-fitting timber connections-experimental and numerical studies on the tapered tenon joint. Eng Struct 48:727-738. https://doi.org/10.1016/j.engstruct. 2012.12.002

11. Claus T, Seim W (2018) Development of the multiple tenon timber connection based on experimental studies and FE simulation. Eng Struct 173(15):331-339. https://doi.org/10.1016/j.engstruct.2018.06.102

12. Japanese Agricultural Standard (2007) JAS for Glued laminated timber. Japanese Agricultural Standards Association, Tokyo (in Japanese)

13. Gustafsson PJ (1988) A study of strength of notched beams. In: Proceedings of the CIB-W18A meeting 21, Paper 21-10-1, Parksville, Canada, 1988

14. Smith I, Springer G (1993) Consideration of Gustafsson's proposed Eurocode 5 failure criterion for notched timber beams. Can J Civil Eng 20(6):1030-1036. https://doi.org/10.1139/193-133

15. NT BUILD 422 (1993) Wood: fracture energy in tension perpendicular to the grain. Nordtest Method, Espoo

16. Ido H, Nagao H, Kato H (2004) Effects of testing methods on characteristic properties of compression perpendicular to the grain of Douglas-fir timber. Bull For For Prod Res Inst 3(4):349-363 (in Japanese)

17. Japan Housing and Wood Technology Center (2017) Allowable stress design for wooden post and beam construction houses. Japan Housing and Wood Technology Center, Tokyo, pp 289-320 (in Japanese)

18. Jockwer R, Serrano E, Gustafsson PJ, Steiger R (2017) Impact of knots on the fracture propagating along grain in timber beams. Int Wood Prod J 8:39-44. https://doi.org/10.1080/20426445.2016.1275093

19. Jockwer R (2014) Structural behaviour of glued laminated timber beams with unreinforced and reinforced notches, Diss. ETH NO. 21825. PhD thesis, Inst of Struct Eng, ETH Zurich, Switzerland, pp 57-58

20. Architectural Institute of Japan (2006) Standard for Structural Design of Timber Structures. Maruzen, Tokyo, p 306, 307, 404 (in Japanese)

21. Larsen HJ, Gustafsson PJ (1990) The fracture energy of wood in tension perpendicular to the grain-results from a joint testing project. In: Proceedings of the CIB-W18A meeting 23, Paper 23-19-2, Lisbon, Portugal, 1990

22. Wood Structure Prom Inc. (2019) Strength data and explanation of wood. Wood Structure Prom Inc, Tokyo, pp 125-127 (in Japanese)

23. JIS Z 2101 (2009) Methods of test for woods. Japanese Standards Association, Osaka (in Japanese)

24. ISO 13910 (2014) Timber structures — strength graded timber-test methods for structural properties. International Organization for Standardization, Geneva

\section{Publisher's Note}

Springer Nature remains neutral with regard to jurisdictional claims in published maps and institutional affiliations. 